Discussion Paper No. 1035

\title{
WEALTH PREFERENCE AND RATIONAL BUBBLES
}

\author{
Jean-Baptiste Michau \\ Yoshiyasu Ono \\ Matthias Schlegl
}

June 2018

The Institute of Social and Economic Research

Osaka University

6-1 Mihogaoka, Ibaraki, Osaka 567-0047, Japan 


\title{
Wealth Preference and Rational Bubbles*
}

\author{
Jean-Baptiste Michau ${ }^{\dagger}$ Yoshiyasu Ono ${ }^{\ddagger}$ Matthias Schlegl ${ }^{\S}$
}

June 2018

\begin{abstract}
We consider a neoclassical economy where households derive utility from holding wealth. We show that, under some conditions, there can be rational bubbles. Hence, we provide a microfoundation for bubbles that relies on a frictionless infinitehorizon economy without any heterogeneity across households. While our bubbly equilibria are very similar to those obtained by Tirole (1985) in an overlapping generation economy, the underlying economics is different. Turning to public debt, we show that Ponzi schemes can be sustainable. Hence, in general, the limit on the accumulation of public debt by the government is not given by its no-Ponzi condition but, instead, by the representative household's transversality condition. The Ricardian equivalence must hold in any of our equilibria. Finally, in the presence of money, the real equilibrium structure of the economy remains unchanged. We carefully investigate the effects of helicopter drops of money on the possibility of Ponzi schemes and of speculative hyperinflation or deflation.
\end{abstract}

Keywords: Ponzi scheme, Rational bubble, Wealth preference

JEL Classification: E13, E44, G12

\section{Introduction}

David Hume, Adam Smith, David Ricardo, Karl Marx, Alfred Marshall, Max Weber, John Maynard Keynes, Frank Knight, and Irving Fisher were all convinced that, for many people, the accumulation of wealth is an end in itself (Steedman 1981, Zou 1994). For instance, Marshall (1890) wrote " There are indeed some who find an intense pleasure

\footnotetext{
*We are grateful to Edouard Challe, Jean-Michel Grandmont, Gerhard Illing, Sisira Jayasuriya and to seminar participants at LMU Munich for helpful comments and suggestions. Financial supports from the Joint Usage Research Center Program and JSPS KAKENHI Grants (JP15H05728 and JP22530178) are gratefully acknowledged.

${ }^{\dagger}$ Ecole Polytechnique, France; jean-baptiste.michau@polytechnique.edu.

${ }^{\ddagger}$ Institute of Social and Economic Research, Osaka University, Japan; ono@iser.osaka-u.ac.jp.

$\S$ JSPS International Research Fellow, Osaka University; LMU University of Munich, Germany; matthias.schlegl@econ.lmu.de.
} 
in seeing their hoards of wealth grow up under their hands, with scarcely any thought for the happiness that may be got from its use by themselves or by others.". However, since the emergence of neoclassical economics in the early 20th century, the standard assumption has been that households only care about wealth because of the future consumption that it can buy. Over the past few years, there has been a growing body of research that has generalized the standard neoclassical framework by assuming that households derive utility from holding wealth. This includes work on the business cycle (Michaillat and Saez 2015), on secular stagnation (Ono 2015, Michau 2018), on the New Keynesian model (Michaillat and Saez 2018), on leverage dynamics (Kumhof, Rancière, and Winant 2015), or on capital taxation (Saez and Stantcheva 2018). In this paper, we investigate the asset pricing implications of the preference for wealth.

Asset prices are composed of two components: a fundamental and a bubble. A well known result (Tirole 1982) is that, in a frictionless economy with a finite number of infinitely-lived households, bubbles are inconsistent with individual rationality. Hence, models of rational bubbles either rely on an overlapping generation (OLG) structure (Samuelson 1958, Tirole 1985) or on financial market imperfections (Woodford 1990, Kocherlakota 1992). In this paper, we show that rational bubbles can exist in a frictionless economy provided that infinitely-lived households derive utility from holding wealth. This theoretical possibility significantly expands the scope for rational bubbles.

We consider a standard Ramsey economy with a finite number of infinitely-lived households, but growing population within each household. Households derive utility from wealth, with a diminishing marginal utility of wealth. This raises their propensity to save to such an extent that the steady state capital stock can exceed the golden rule level. ${ }^{1}$ In that case, there is a bubbly equilibrium that induces the steady state capital stock to coincide with the golden rule.

While our bubbly equilibria are very similar to those obtained by Tirole (1985) in an OLG economy, the underlying mechanism is fundamentally different. In a simple OLG economy, the bubble acts as a coordinating mechanism across generations whereby the old of each cohort exchange the bubbly asset against consumption goods produced by the young of the following cohort. ${ }^{2}$ By contrast, in our framework, infinitely-lived households (or dynasties) want to accumulate wealth without the intention of spending it. Hence, they can be willing to pay more for an asset than its fundamental value, which could make a bubble sustainable over time. We therefore provide an alternative narrative for

\footnotetext{
${ }^{1}$ We avoid using the term "dynamic inefficiency" since, in our setup, if the capital stock is above the golden rule and bubbles cannot exist (as in Section 3 below), then there is no Pareto improving reallocation of resources.

${ }^{2}$ Similarly, in the perpetual youth model $\grave{a} l a$ Blanchard (1985) and Yaari (1965), the possibility of rational bubble is due to the birth of new individuals who will subsequently buy some of the bubbly asset (Weil 1989).
} 
the existence of rational bubbles.

In both cases, we cannot have an equilibrium where the bubble grows without bounds. But the underlying reason is again different. In the OLG economy, this is due to the fact that, if the bubble grows over time, then it eventually becomes larger than the income of the young who buy it, which is clearly unfeasible. In our economy, as the bubble grows to infinity, the marginal utility of wealth converges to zero, which brings us back to the standard neoclassical case where the transversality condition rules out bubbles.

Hence, in both cases, a bubbly steady state must be characterized by a bubble of constant size relative to population. Moreover, by arbitrage with other risk-free assets, the bubble must grow at the real interest rate. Hence, in a bubbly steady state, the interest rate must be equal to the population growth rate and the capital stock must therefore be at the golden rule. Thus, the fact that the steady state bubble implements the golden rule in both Tirole (1985) and in our economy is due to the stationarity requirement and is largely independent of the economic mechanism leading to the very existence of the bubble.

Note that, with constant marginal utility of wealth, rational bubbles can occur even when the capital stock is below the golden rule. In that case, the interest rate is above the population growth rate and the rational bubble grows without bounds. The insatiability of the preference for wealth implies that, even with an ever growing asset price, the transversality condition is satisfied.

In environments where rational bubbles are possible, we know that Ponzi schemes of government debt can be sustainable. Fundamentally, the only limit to government indebtedness is imposed by the representative household's willingness to lend to it. Hence, in general, the government budget constraint is not given by the no-Ponzi condition but instead by the household's transversality condition. Note that, in the standard neoclassical framework, the two conditions are equivalent to each other. But, this equivalence breaks down when households have a preference for wealth. ${ }^{3}$ This makes it possible to obtain a steady state equilibrium that violates the government's no-Ponzi condition. However, in such cases, there must also exist an equilibrium where households do not want to lend to the government beyond its no-Ponzi condition.

In any equilibrium of the economy, the Ricardian equivalence holds, i.e. the timing of tax collection is neutral. This is a fundamental difference with other models of rational bubbles. In models based on the OLG structure or on financial frictions, bubbles exist to redistribute resources across people. Hence, the very existence of bubbles relies on the non-Ricardian nature of these models. By contrast, our work shows that the existence of

\footnotetext{
${ }^{3}$ In the perpetual youth model, the equivalence between the government's no-Ponzi condition and the aggregation of households' transversality conditions also fails to hold, but this is due to the birth of new individuals.
} 
rational bubbles is not fundamentally inconsistent with the Ricardian equivalence.

The presence of money does not affect the real equilibrium structure of the economy. The preference for wealth remains solely responsible for the possibility of Ponzi schemes, while money-in-the-utility-function only affects nominal variables. In the special case where money is the only asset supplied by the government, through helicopter drops, the growth rate of the nominal money supply simultaneously affects the possibility of Ponzi schemes, on the real side, and of speculative deflation, on the nominal side. But, any real allocation of resources that can be implemented through helicopter drops of money can also be implemented through an appropriate fiscal policy.

Following Japan's lost decade or the Great Recession in the U.S. and in the eurozone, there has been concerns that these economies were trapped into demand-driven secular stagnation characterized by a permanently depressed interest rate. ${ }^{4}$ In these circumstances, asset and government debt prices can permanently depart from their fundamental values. And, indeed stock market valuations have been unusually high in the U.S. while the Japanese debt-to-GDP ratio has exceeded $250 \%$ without triggering any increase in long term interest rates. Our work shows that there is no need to invoke either financial frictions or an overlapping generation structure (without altruistic links) to reconcile these patterns with rational optimizing behavior.

Related Literature. In a seminal paper, Tirole (1982) has shown that a bubble cannot exist if the following two conditions simultaneously hold: (i) there is a finite number of infinitely-lived households, and (ii) the economy is frictionless. Naturally, models of rational bubbles rely on the violation of at least one of these two assumptions. By contrast, we obtain rational bubbles, not by relaxing the two key assumptions of Tirole (1982), but instead by generalizing the standard neoclassical framework through the introduction of a preference for wealth.

Samuelson (1958) was the first to establish the possibility of rational bubbles within an OLG economy. The result was subsequently generalized by Wallace (1980). While both had exclusively focused on monetary bubbles within endowment economies, Tirole (1985) characterized the set of bubbly equilibria within a real production economy à la Diamond (1965). He established that bubbles can exist provided that, in their absence, the economy would be dynamically inefficient. ${ }^{5}$ Importantly, Weil (1989) has shown that it is the birth of new households with zero wealth, rather than the finiteness of life, that is responsible for the possibility of bubbles. ${ }^{6}$

\footnotetext{
${ }^{4}$ See Ono (2015) and Michau (2018) for models of secular stagnation with wealth in the utility.

${ }^{5}$ Also, O'Connell and Zeldes (1988) derived very general existence conditions for rational bubbles and proved some equivalence results between rational bubbles, Ponzi schemes, and valuable fiat money.

${ }^{6}$ More fundamentally, Shell (1971) considered an example of a static economy with an infinity of households and of commodities. He showed that, despite the existence of complete markets, the decentralized equilibrium could be Pareto inefficient. As this economy is isomorphic to an OLG economy, it
} 
By arbitrage, a bubble must grow at the real interest rate. But, explosive bubbles are not feasible. Hence, the interest rate must be smaller than the growth rate of the economy, i.e. the economy must be dynamically inefficient. Empirically, however, it is not clear that the capital stock is above the golden rule. ${ }^{7}$ Hence, to obtain a rational bubble in a dynamically efficient economy, a number of theories have been proposed to raise the social returns on investment above the interest rate. This allows the growth rate of the economy to simultaneously be smaller than the social returns on investment, as required by dynamic efficiency, and larger than the interest rate, as required to have a non-explosive bubble.

Thus, to generate a rational bubble in a dynamically efficient economy, Saint-Paul (1992), Grossman and Yanagawa (1993), and King and Ferguson (1993) have introduced endogenous growth within the OLG framework. The presence of externalities in capital accumulation raise the social returns on investment above the interest rate. Alternatively, Woodford (1990) and Azariadis and Smith (1993) introduced financial frictions in an OLG economy. Again, the financial frictions raise the returns on investment above the interest rate. Interestingly, in an OLG economy with financial frictions, a bubble can raise economic activity by reallocating resources from unproductive to productive agents (Martin and Ventura 2012) or from unproductive to productive time periods (Farhi and Tirole 2012). In all these papers, bubbles are due to the OLG structure of the economy, not to the presence of financial frictions.

An alternative strand of the literature builds on Scheinkman and Weiss (1986), Woodford (1990), Kocherlakota (1992, 2008), Santos and Woodford (1997), and Hellwig and Lorenzoni (2009) who have shown that financial frictions alone can generate rational bubbles. Importantly, this can reconcile bubbles with a finite number of infinitely-lived individuals. ${ }^{8}$ Miao and Wang $(2014,2017)$ and Hirano and Yanagawa (2017) generalized these results to production economies. Interestingly, Miao and Wang (2014, 2017) showed that stock price bubbles generate a "collateral yield", which allows bubbles to grow at a slower rate than the interest rate. Finally, Aoki, Nakajima, and Nikolov (2014) showed that bubbles can result from uninsurable idiosyncratic risk, rather than from credit constraints. In their setup, the market incompleteness depresses the interest rate below the growth rate of the economy.

In the whole literature, rational bubbles are fundamentally due to heterogeneity across

follows that the possibility of dynamic inefficiency and rational bubbles is due to the existence of an infinite number of households and commodities, not to a market incompleteness. (See also Acemoglu 2009 , chapter 9 , for a discussion of how this relates to the fundamental welfare theorems.)

${ }^{7}$ Abel, Mankiw, Summers, and Zeckhauser (1989) established empirically that the U.S. economy is dynamically efficient. More recently, Geerolf (2017) found that many industrialized economies are now likely to be dynamically inefficient.

${ }^{8}$ In a recent assessment of the literature, Miao (2016) argued that "developing infinite-horizon models of bubbles is important for us to further understand asset bubbles both qualitatively and quantitatively". 
agents. In the OLG framework, their is heterogeneity across cohorts; while under financial frictions, their is heterogeneity between creditors and debtors. In both strands of the literature, bubbles exist to transfer resources across individuals. This is clearly not the case within our representative household model, which is why the Ricardian equivalence holds. We therefore provide a new microfoundation for rational bubbles. This provides a straightforward way of generating bubbles within standard representative household frameworks. ${ }^{9}$

Finally, there is a small literature on wealth preferences and bubbles. Ono (1994, chapter 11) was the first to show that, if households are characterized by an insatiable preference for wealth (which he interprets as a preference for liquidity), then an asset price can have a bubble component that diverges to infinity. However, he only considered an endowment economy, which implies that the bubble could not interact with capital accumulation.

Kamihigashi (2008) independently proved a similar result for an endowment economy. He then considered a production economy. However, by not allowing for depreciation of capital, he constrained the interest rate to be positive, which ruled out steady state bubbles. Thus, the only possibility was to have an explosive bubble. Interestingly, he showed that a bubble reduces capital accumulation under decreasing returns to capital, but it fosters capital accumulation under increasing returns.

Importantly, both Ono (1994) and Kamihigashi (2008) could only obtain explosive bubbles under an insatiable preference for wealth, i.e. under the assumption that the marginal utility of wealth converges to a strictly positive value as wealth tends to infinity. By contrast, Zhou (2016) showed that a steady state bubble on a zero-dividend asset is possible when the marginal utility of wealth converges to zero as wealth tends to infinity. He considered a production economy and found that a bubble could only arise if the capital stock is above the golden rule. However, he only established his results for a specific parametric case for which he could derive an explicit analytical solution. We instead consider the general case and allow for different growth rates of dividends. The only substantive restriction that we impose is that the household's utility function is additively separable between consumption and wealth. ${ }^{10}$

Our paper is organized as follows. In Section 2, we briefly motivate the preference for

\footnotetext{
${ }^{9}$ There has recently been a rising interest in macroeconomics for the monetary policy consequences of bubbles (Gali 2014, 2017, Asriyan, Fornaro, Martin, and Ventura 2016, Allen, Barlevy, and Gale 2017, Dong, Miao, and Wang 2017, Ikeda 2017, Hanson and Pahn 2017, Biswas, Hanson, and Phan 2018). In many of these papers, especially those relying on an OLG structure, the dimensions of heterogeneity necessary to generate a rational bubble are largely orthogonal to the issue of monetary policy under investigation.

${ }^{10}$ Relying on parametric examples within an endowment economy, Airaudo (2017) showed that, without additive separability, the preference for wealth can generate extremely complex, and even chaotic, asset price dynamics.
} 
wealth. The structure of our neoclassical economy is presented in Section 3. We introduce an infinitely-lived asset in Section 4, which generates the possibility of bubbles. Section 5 considers government debt. We investigate a nominal economy with money in the utility function in Section 6. The paper ends with a conclusion. All proofs are relegated to the appendix.

\section{Wealth Preference}

Beyond the reflection of classical economists mentioned at the beginning of the introduction, different strands of the modern literature in economics do provide support for the preference for wealth.

Empirically, many wealthy households consume persistently less than their permanent income. Carroll (2000) argued that the most natural explanation is that these households derive utility from holding wealth. ${ }^{11}$ Dynan, Skinner, and Zeldes (2004) also found that households with higher lifetime income paradoxically have higher lifetime saving rates. More recently, Straub (2018) estimated that the propensity to consume out of permanent income is around 0.7 and, therefore, much below 1 . Such findings can in fact be used to calibrate the utility derived by households from their holdings of wealth (Kumhof, Rancière, and Winant 2015).

Bequest motives are important determinants of the savings behavior of infinitely-lived households (or dynasties). But, we know that pure altruism alone cannot account for the observed pattern of bequests (Carroll 2000, Kopczuk 2009). It has therefore become common to assume that parents derive utility from the amount of bequeathed wealth, which is usually interpreted as a "joy of giving" or as a "capitalist spirit". Importantly, our work shows that rational bubbles or Ponzi schemes are a theoretical possibility within these dynastic economies.

This brings us to quantitative models of wealth inequalities. Incorporating a bequest motive, i.e. utility from bequeathed wealth, is typically necessary to account for the high concentration of wealth that we observe empirically (De Nardi 2004, Cagetti and De Nardi 2006, Benhabib, Bisin and Luo 2017). Piketty (2011) also relies on a model with a preference for wealth to show that the inheritance-to-income ratio is a rising function of $r-g$, consistent with the historical experience of France from 1820 to 2009. Also, Kumhof, Rancière, and Winant (2015) showed that the preference for wealth of high income households can account for the increase in debt leverage of low and middle income households in the run-up to the Great Recession. In all these papers, the role of

\footnotetext{
${ }^{11}$ Note that, to obtain our results, we only need that a fraction of households have a preference for wealth. Indeed, with heterogeneous agents, thrifty households lend to impatient households until the latter are borrowing constrained. Hence, the interest rate and asset prices are eventually determined by the behavior of thrifty households, i.e. by those who have a preference for wealth.
} 
the preference for wealth is to raise the propensity to save of wealthy households, in line with empirical observations.

Finally, Bakshi and Chen (1996) were the first to investigate the asset pricing implications of the preference for wealth. Focusing on risky assets, they showed that the preference for wealth raises the impact of asset returns on households' utility, thereby raising the perceived riskiness of stocks. They found that the resulting model does a better job at explaining asset prices than the standard neoclassical model. However, Bakshi and Chen (1996) did not consider the possibility of bubbles.

The preference for wealth is not only a plausible assumption according to classical economists, it is also a serious candidate explanation for a number of empirical regularities. It is therefore a natural generalization of the standard neoclassical framework. ${ }^{12}$

\section{Economy without Infinitely-Lived Assets}

In this section, we present our framework and derive the equilibrium of the economy in the absence of infinitely-lived assets (and therefore in the absence of bubbles).

\subsection{Households}

Time is continuous. There is a mass 1 of infinitely lived households. Population within each household grows at rate $n$. The total population of the economy is therefore given by $N_{t}=e^{n t}$. At any time $t$, the representative household consumes a quantity $N_{t} c_{t}$ of a single consumption good and inelastically supplies labor $N_{t}$ at wage $w_{t}$. Let $\mathcal{A}_{t}$ denote the household wealth, which is composed of physical capital $K_{t}$ and risk-free bonds $\mathcal{B}_{t}$ :

$$
\mathcal{A}_{t}=K_{t}+\mathcal{B}_{t}
$$

Firms pay $R_{t}$ to rent capital from households. Capital depreciates at rate $\delta$. Bonds yield a return $r_{t}$. Finally, in addition to the output produced from capital and labor, the economy receives an exogenous endowment of goods $z N_{t}$ at each point in time. It is given to households in a lump-sum fashion. This endowment is not important for now, but will play a key role in the next section when we introduce an infinitely-lived asset.

\footnotetext{
${ }^{12}$ There is also a literature on status preference, according to which welfare is increasing in relative wealth (see, for instance, Zhou 2016, Ono and Yamada 2018). However, investigating how the different specifications of the relative wealth preference affect the possibility of rational bubbles is beyond the scope of this paper.
} 
Household wealth therefore evolves according to:

$$
\begin{aligned}
\dot{\mathcal{A}}_{t} & =\left[R_{t}-\delta\right] K_{t}+r_{t} \mathcal{B}_{t}+w_{t} N_{t}+z N_{t}-c_{t} N_{t}, \\
& =r_{t} \mathcal{A}_{t}+w_{t} N_{t}+z N_{t}-c_{t} N_{t}+\left[R_{t}-\delta-r_{t}\right] K_{t} .
\end{aligned}
$$

By arbitrage, the returns on capital must be equal to the returns on bonds. It follows that:

$$
r_{t}=R_{t}-\delta
$$

Let $a_{t}=\mathcal{A}_{t} / N_{t}, k_{t}=K_{t} / N_{t}$, and $b_{t}=\mathcal{B}_{t} / N_{t}$ denote wealth per capita, capital per capita, and bonds per capita, respectively. We therefore have:

$$
a_{t}=k_{t}+b_{t}
$$

Hence, $\dot{a}_{t}=\dot{\mathcal{A}}_{t} / N_{t}-n a_{t}$, which implies that:

$$
\dot{a}_{t}=\left(r_{t}-n\right) a_{t}+w_{t}+z-c_{t}
$$

Finally, households are subject to an intertemporal budget constraint that prevents them from running Ponzi schemes:

$$
\lim _{t \rightarrow \infty} e^{-\int_{0}^{t}\left(r_{s}-n\right) d s} a_{t} \geq 0
$$

The representative household discounts the future at rate $\rho$, with $\rho>n$. At any point in time, it derives utility $u\left(c_{t}\right)$ from consuming $c_{t}$, with $u^{\prime}(\cdot)>0, u^{\prime \prime}(\cdot)<0$, and $\lim _{c \rightarrow 0} u^{\prime}(c)=\infty$. The household also derives utility $\gamma\left(a_{t}\right)$ from holding wealth $a_{t}$, with $\gamma^{\prime}(\cdot)>0, \gamma^{\prime \prime}(\cdot)<0, \gamma^{\prime}(0)<\infty$, and $\lim _{k \rightarrow \infty} \gamma^{\prime}(k)=0$. The household's intertemporal utility function is therefore given by:

$$
\int_{0}^{\infty} e^{-(\rho-n) t}\left[u\left(c_{t}\right)+\gamma\left(a_{t}\right)\right] d t
$$

The household maximizes its intertemporal utility (7) subject to its budget constraint (5) and (6) with $a_{0}$ given. By the maximum principle, the solution to the household's problem is characterized by:

$$
\frac{\dot{c}_{t}}{c_{t}}=\left[r_{t}-\rho+\frac{\gamma^{\prime}\left(a_{t}\right)}{u^{\prime}\left(c_{t}\right)}\right] \frac{u^{\prime}\left(c_{t}\right)}{-u^{\prime \prime}\left(c_{t}\right) c_{t}}
$$

together with the transversality condition:

$$
\lim _{t \rightarrow \infty} e^{-(\rho-n) t} u^{\prime}\left(c_{t}\right) a_{t}=0
$$




\subsection{Firms}

Firms rent capital $K_{t}$ from households and employ labor $N_{t}$ to produce output $Y_{t}$ using a constant returns to scale neoclassical production function:

$$
Y_{t}=F\left(K_{t}, N_{t}\right)
$$

They choose their demand for capital $K_{t}$ and for labor $N_{t}$ such as to maximize their profits:

$$
F\left(K_{t}, N_{t}\right)-R_{t} K_{t}-w_{t} N_{t}
$$

In equilibrium, each factor of production must be paid its marginal product:

$$
\begin{aligned}
& R_{t}=F_{K}\left(K_{t}, N_{t}\right), \\
& w_{t}=F_{N}\left(K_{t}, N_{t}\right) .
\end{aligned}
$$

Let $y_{t}=Y_{t} / N_{t}$ denote production per capita and define $f(k)=F(k, 1)$ for any $k$. We therefore have $y_{t}=f\left(k_{t}\right), R_{t}=f^{\prime}\left(k_{t}\right)$, and $w_{t}=f\left(k_{t}\right)-k_{t} f^{\prime}\left(k_{t}\right)$. The real interest rate $r_{t}$ is equal to the rental cost of capital $R_{t}$ net of depreciation $\delta$, which implies $r_{t}=f^{\prime}\left(k_{t}\right)-\delta$.

\subsection{Market Clearing}

The goods market clearing condition imposes that total output must be equal to the sum of consumption and investment:

$$
Y_{t}+z N_{t}=c_{t} N_{t}+\left[\delta K_{t}+\dot{K}_{t}\right]
$$

As $\dot{k}_{t}=\dot{K}_{t} / N_{t}-n k_{t}$ and $Y_{t}=N_{t} y_{t}=N_{t} f\left(k_{t}\right)$, we must have:

$$
\dot{k}_{t}=f\left(k_{t}\right)+z-c_{t}-(\delta+n) k_{t} .
$$

Also, bonds are in zero net supply. Hence, in equilibrium, $b_{t}=0$ and $a_{t}=k_{t}$. 


\subsection{Equilibrium}

The equilibrium of the economy $\left(c_{t}, k_{t}\right)_{t=0}^{\infty}$ is fully characterized by:

$$
\begin{gathered}
\frac{\dot{c}_{t}}{c_{t}}=\left[f^{\prime}\left(k_{t}\right)-\delta-\rho+\frac{\gamma^{\prime}\left(k_{t}\right)}{u^{\prime}\left(c_{t}\right)}\right] \frac{u^{\prime}\left(c_{t}\right)}{-u^{\prime \prime}\left(c_{t}\right) c_{t}}, \\
\dot{k}_{t}=f\left(k_{t}\right)+z-c_{t}-(\delta+n) k_{t}, \\
\lim _{t \rightarrow \infty} e^{-(\rho-n) t} u^{\prime}\left(c_{t}\right) k_{t}=0,
\end{gathered}
$$

$k_{0}$ given.

Note that, under the capital market clearing condition $a_{t}=k_{t}$, the household's noPonzi condition (6) is trivially satisfied. It has therefore been omitted from the list of equilibrium conditions.

A steady state equilibrium $(c, k)$ is characterized by:

$$
\begin{gathered}
\gamma^{\prime}(k)=\left[\rho+\delta-f^{\prime}(k)\right] u^{\prime}(c), \\
c=f(k)+z-(\delta+n) k .
\end{gathered}
$$

Let us now introduce an assumption that we will use throughout our analysis.

Assumption 1 The equation $\gamma^{\prime}(k+\alpha)=\left[\rho+\delta-f^{\prime}(k)\right] u^{\prime}(f(k)+z-(\delta+n) k) d e-$ fines $\alpha$ as a decreasing function of $k$ for all admissible values of $k$.

This is implicitly an assumption on the functional forms for $u(\cdot), \gamma(\cdot)$, and $f(\cdot)$. It implies that an exogenous increase in wealth $\alpha$ reduces the household's propensity to save and therefore reduces the corresponding steady state capital stock $k$. Not only is it the natural economic scenario to expect, it is also technically a very mild condition. Totally differentiating this equation with respect to $k$ reveals that Assumption 1 must be satisfied for any given function forms for $u(\cdot), \gamma(\cdot)$, and $f(\cdot)$ provided that $\rho$ is sufficiently close to $n$.

Lemma 1 A steady state equilibrium always exists and, under Assumption 1, it must be unique.

We shall now consider throughout our analysis that Assumption 1 is satisfied (but we explicitly refer to it in the proofs whenever it is being used).

Let $\bar{r}$ denote the steady state natural interest rate, defined as the steady state interest rate of the economy with no infinitely-lived asset. It is simply given by:

$$
\begin{aligned}
\bar{r} & =f^{\prime}(k)-\delta \\
& =\rho-\frac{\gamma^{\prime}(k)}{u^{\prime}(c)} .
\end{aligned}
$$


This implies that $\bar{r} \in(-\delta, \rho)$.

By (21), the golden rule capital stock $k^{*}$, which maximizes steady state consumption, is characterized by:

$$
f^{\prime}\left(k^{*}\right)=\delta+n
$$

Thus, the steady state capital stock $k$ is above the golden rule level $k^{*}$ whenever:

$$
\bar{r}=f^{\prime}(k)-\delta<f^{\prime}\left(k^{*}\right)-\delta=n
$$

A sufficiently strong preference for wealth $\gamma(\cdot)$ can easily result in a steady state equilibrium with $\bar{r}<n$. In that case, households choose to accumulate more capital than under the golden rule since, in the absence of alternative stores of value, they have no other way to satisfy their preference for wealth. Note that, without a preference for wealth, we would have $\bar{r}=\rho>n$. Hence, it is the preference for wealth that can induce the capital stock to exceed the golden rule level.

\section{Infinitely-Lived Asset}

To allow for the possibility of rational bubbles, let us now introduce an infinitely-lived asset into this economy. At any time $t$, a fraction $e^{-\theta t}$ of the exogenous endowment $z N_{t}$ accrues to the owners of the single infinitely-lived asset of the economy, where $\theta \geq 0$. The remaining fraction, $1-e^{-\theta t}$, is given to the representative household in a lump-sum fashion, as in the previous section.

Thus, relative to the size of the economy, the dividends shrink at rate $\theta$. This could, for instance, result from gradually depreciating technologies or patents. Three benchmarks are of particular interest. If $\theta=0$, then the dividends grow at the same speed as the economy. If $\theta=n$, then the dividends are constant in real terms, as in Tirole (1985). Finally, in the limit as $\theta$ tends to infinity, the asset does not yield any dividends and is therefore intrinsically worthless. ${ }^{13}$

Let $Q_{t}$ denote the price of the asset. The returns on the ownership of the asset consist of the dividends $z N_{t} e^{-\theta t}=z e^{(n-\theta) t}$ and of the capital gains $\dot{Q}_{t}$. By arbitrage, these returns must be equal to the returns on risk-free bonds:

$$
z e^{(n-\theta) t}+\dot{Q}_{t}=r_{t} Q_{t}
$$

Let $q_{t}=Q_{t} / N_{t}$ denote the price per capita of the asset. As $\dot{q}_{t}=\dot{Q}_{t} / N_{t}-n q_{t}$, we must

\footnotetext{
${ }^{13}$ If firms are infinitely lived, then equity can be an infinitely-lived asset. However, under a constant returns to scale production function, the dividends are equal to zero. Equity would therefore be intrinsically worthless. The equilibrium with equity would be identical to the equilibrium with $\theta=\infty$.
} 
have:

$$
\dot{q}_{t}=\left(r_{t}-n\right) q_{t}-z e^{-\theta t} .
$$

Household wealth $a_{t}$ consists of physical capital $k_{t}$, risk-free bonds $b_{t}$, and of the asset with value $q_{t}$. Thus, in equilibrium:

$$
a_{t}=k_{t}+b_{t}+q_{t}
$$

The net supply of bonds is equal to zero. So, in equilibrium, $b_{t}=0$. As the asset can be freely disposed of, we must always have $q_{t} \geq 0$. Hence, with $a_{t}=k_{t}+q_{t}$, the household's no-Ponzi condition (6) is trivially satisfied. The equilibrium of the economy $\left(c_{t}, k_{t}, q_{t}\right)_{t=0}^{\infty}$ is therefore fully characterized by:

$$
\begin{gathered}
\frac{\dot{c}_{t}}{c_{t}}=\left[f^{\prime}\left(k_{t}\right)-\delta-\rho+\frac{\gamma^{\prime}\left(k_{t}+q_{t}\right)}{u^{\prime}\left(c_{t}\right)}\right] \frac{u^{\prime}\left(c_{t}\right)}{-u^{\prime \prime}\left(c_{t}\right) c_{t}}, \\
\dot{k}_{t}=f\left(k_{t}\right)+z-c_{t}-(\delta+n) k_{t}, \\
\dot{q}_{t}=\left(f^{\prime}\left(k_{t}\right)-\delta-n\right) q_{t}-z e^{-\theta t}, \\
\lim _{t \rightarrow \infty} e^{-(\rho-n) t} u^{\prime}\left(c_{t}\right)\left[k_{t}+q_{t}\right]=0, \\
k_{0} \text { given. }
\end{gathered}
$$

Before we characterize the equilibria of the economy, it is useful to decompose the asset price $q_{t}$ into a fundamental component $\mu_{t}$ and a bubble component $\eta_{t}$. The fundamental component is the solution to:

$$
\dot{\mu}_{t}=\left(f^{\prime}\left(k_{t}\right)-\delta-n\right) \mu_{t}-z e^{-\theta t}
$$

subject to the no-bubble boundary condition:

$$
\lim _{T \rightarrow \infty} e^{-\int_{t}^{T}\left(f^{\prime}\left(k_{u}\right)-\delta-n\right) d u} \mu_{T}=0
$$

This immediately implies that:

$$
\mu_{t}=z e^{-\theta t} \int_{t}^{\infty} e^{-\int_{t}^{s}\left(f^{\prime}\left(k_{u}\right)-\delta-n+\theta\right) d u} d s
$$

The fundamental price of the asset is equal to the present value of the dividend stream generated by the asset. The bubble component is the solution to:

$$
\dot{\eta}_{t}=\left(f^{\prime}\left(k_{t}\right)-\delta-n\right) \eta_{t}
$$

By arbitrage, the bubble component must grow at the rate of interest net of population 
growth. It must therefore be equal to:

$$
\eta_{t}=e^{\int_{0}^{t}\left(f^{\prime}\left(k_{u}\right)-\delta-n\right) d u} \eta_{0}
$$

Thus, any bubble must be indexed by $\eta_{0}$. If $\eta_{0}=0$, there is no bubble; if $\eta_{0}>0$, there is a positive bubble; and if $\eta_{0}<0$ there is a negative bubble. Finally, the price of the asset is simply given by:

$$
q_{t}=\mu_{t}+\eta_{t}
$$

\subsection{Steady State}

A steady state equilibrium is characterized by $c_{t}=c$ and $k_{t}=k$ for all $t$. We must also have $r_{t}=r$ for all $t$, with $r$ given by:

$$
r=f^{\prime}(k)-\delta
$$

Before characterizing the steady state equilibria of the economy, we establish a number of properties of the asset price in steady state.

Is it possible to have a steady state with an ever growing asset price? The answer is no.

Lemma 2 There cannot be a steady state equilibrium with an ever growing asset price $q_{t}$.

As the asset price becomes infinitely large, the marginal utility of wealth converges to zero and, by the consumption Euler equation (28), the interest rate converges to $\rho$. Hence, by the asset pricing equation (30), the asset price must asymptotically grow at rate $\rho-n$. But, under such rapidly growing household wealth, the transversality condition (31) imposes an infinitely high demand for consumption. This is ruled out by the resource constraint (29). Hence, in steady state, we must have $q_{t}=q$ for all $t$.

Before characterizing the steady state equilibria of the economy, we establish an important property of the economy with infinitely-lived assets.

Lemma 3 The steady state interest rate $r$ cannot be smaller or equal to $n-\theta$.

The fundamental price of the asset is not well defined when the growth rate of rents $-\theta$ is larger than the interest rate net of population growth $r-n$. We must therefore have $r>n-\theta$. This implies that the existence of capitalizable rents $z e^{-\theta t}$, no matter how small, constrains the steady state interest rate of the economy to be above $n-\theta$.

In the presence of a bubble, the asset price can either be above or below its fundamental value. However, the following lemma rules out negative bubbles. 
Lemma 4 Under the steady state interest rate $r>n-\theta$, there cannot be a negative bubble.

In steady state, the bubble component grows at rate $r-n$, while the fundamental component grows at rate $-\theta$. Hence, the bubble component grows at a higher rate than the fundamental component. It follows that a negative bubble would grow so fast that the asset price would eventually become negative. But, this is not possible as the asset can be freely disposed of. Note that, if there cannot be a negative bubble in steady state, then there also cannot be a negative bubble on any trajectory converging to a steady state. ${ }^{14}$

Let us now characterize the steady state equilibria $(c, k, q)$ of the economy. From $(28)$ and (29), we must have:

$$
\begin{gathered}
\gamma^{\prime}(k+q)=\left[\rho+\delta-f^{\prime}(k)\right] u^{\prime}(c), \\
c=f(k)+z-(\delta+n) k .
\end{gathered}
$$

Regarding the third equation characterizing the steady state, (30), we must distinguish two cases: $\theta=0$ and $\theta>0$.

When $\theta=0$, the dividends grow at the same speed as the economy. In that case, by (30):

$$
q=\frac{z}{f^{\prime}(k)-\delta-n} .
$$

Thus, when $\theta=0$, the price of the asset must be equal to its fundamental value. In equilibrium, we must have $q \in[0, \infty)$. Hence $r=f^{\prime}(k)-\delta>n$, which implies that the steady state capital stock must be smaller than under the golden rule. The following proposition refers to $\bar{r}$, which was defined in the previous section as the steady state interest rate of the economy without infinitely-lived assets.

Lemma 5 When $\theta=0$, there always exists a unique steady state equilibrium, which is characterized by (40), (41), and (42). It must be bubble-less and it must satisfy $r>$ $\max \{\bar{r}, n\}$.

If the rent $z$ could not be capitalized, then we would be back to the previous section with a steady state interest rate equal to $\bar{r}$. The fact that, here, the rent $z$ can be capitalized raises household wealth by $q$, which increases the demand for consumption and reduces the accumulation of capital. This raises the interest rate $r$ above $\bar{r}$.

Why is it impossible to have a bubbly steady state when $\theta=0$ ? Recall that bubbles always grow at rate $r-n$. But, we have just seen that the fundamental value of the asset

\footnotetext{
${ }^{14}$ From the expression for the bubble component (37), if the bubble is negative at some point in time, then it must always be negative.
} 
is only well defined if $r=f^{\prime}(k)-\delta>n$ (which is also implied by Lemma 3). Thus, a bubble would grow forever, which by Lemma 2 is not possible.

Let us now turn to the case where $\theta>0$. From (30), in steady state, we must either have:

$$
f^{\prime}(k)-\delta=n
$$

or:

$$
q=0
$$

The first case corresponds to a bubbly equilibrium, which results in a constant asset price per capita; while the second case corresponds to the asset being worth its fundamental value, which asymptotically converges to zero whenever $\theta>0$.

When $f^{\prime}(k)-\delta=n$, a bubble induces the interest rate to be equal to the rate of population growth and, hence, the capital stock to be equal to the golden rule level. However, by Lemma 4, a bubble must always raise the price of the asset above its fundamental value. This must reduce the household's propensity to save and therefore decrease the capital stock. Hence, the bubbly equilibrium can only occur if the steady state capital stock in the economy without the infinitely-lived asset is larger than under the golden rule, i.e. if $\bar{r}<n$.

Lemma 6 When $\theta>0$, there (asymptotically) exists a unique bubbly steady state equilibrium if and only if $\bar{r}<n$. It is characterized by (40), (41), and (43) and it satisfies $r=n$.

The steady state equilibrium only exists asymptotically as $z e^{-\theta t}$ is only equal to zero in the limit as $t$ tends to infinity.

Note that, in the bubbly steady state, the asset price $q_{t}$ must be constant over time. This requires $r=n$ and a capital stock equal to the golden rule. The steady state asset price $q$ is therefore entirely determined by the preference for wealth through the consumption Euler equation (40).

In the alternative case, where $q=0$, the equilibrium is unchanged from the previous section without any infinitely-lived asset. However, as shown by Lemma 3, the very existence of a single infinitely-lived asset prevents the interest rate from being smaller or equal to $n-\theta$. Hence, this equilibrium is only meaningful when $\bar{r}>n-\theta$. Indeed, while $\theta$ is irrelevant in the limit as $t$ tends to infinity, we must have $\bar{r}>n-\theta$ for any finite value of $t$.

Lemma 7 When $\theta>0$, there (asymptotically) exists a unique bubble-less steady state equilibrium, which is characterized by (40), (41), and (44). It satisfies $r=\bar{r}$. This asymptotic steady state is economically meaningful if and only if $\bar{r}>n-\theta$. 
The existence and uniqueness of this equilibrium trivially follows from Lemma 1 of the previous section.

When the two steady states simultaneously exist, they can be Pareto ranked.

Lemma 8 When $\theta>0$ and $\bar{r} \in(n-\theta, n)$, the bubbly steady state equilibrium is Pareto superior to the bubble-less steady state.

The bubble allows households to have a store of value, such as to satisfy their preference for wealth, without over-accumulating capital. Here, as in a dynamically inefficient overlapping generation economy, steady state bubbles are perfectly efficient. ${ }^{15}$

Let us now investigate the stability properties of these steady state equilibria.

\subsection{Stability}

To determine the local stability properties of the steady state equilibria, we linearize the system of differential equations (28), (29), and (30) around these steady states. Let us first investigate the stability of the steady state equilibrium when $\theta=0$.

Lemma 9 When $\theta=0$, the unique steady state equilibrium is locally saddle-path stable. For a given $k_{0}$, there is a unique trajectory converging to the steady state. This trajectory is bubble-less.

As there cannot be a bubble along the trajectory converging to the steady state, the asset must always be worth its fundamental value.

When $\theta>0$, the system of differential equations is not homogenous and not autonomous, due to the $z e^{-\theta t}$ term in (30). However, as this term tends to zero over time, it does not fundamentally change the stability analysis.

Lemma 10 When $\theta>0$, the ze $e^{-\theta t}$ term in (30) does not modify the local stability analysis of the linearized system of differential equations.

Thus, when $\theta>0$, the local stability of a steady state equilibrium is determined by the eigenvalues of the transition matrix of the linearized system of differential equations, as would be the case in the absence of the $z e^{-\theta t}$ term.

When $\theta>0$, one steady state equilibrium is bubbly, the other is not. The bubbly steady state exists whenever $\bar{r}<n$.

\footnotetext{
${ }^{15}$ If wealth $a_{t}$ is constrained to be equal to the physical capital stock $k_{t}$, as in Section 3 , then the first fundamental theorem applies and the equilibrium allocation is Pareto efficient. However, if wealth can also consist of financial wealth, as in this section, then welfare is directly affected by asset prices and the first fundamental theorem does not hold. This is another fundamental difference with the OLG economy, where the failure of the first fundamental theorem is due to an infinity problem (see footnote 6).
} 
Lemma 11 When $\theta>0$, the bubbly steady state equilibrium is locally saddle-path stable. For a given $k_{0}$, there is a unique trajectory converging to the steady state. This trajectory is bubbly.

Let us now turn to the stability of the bubble-less steady state, which exists whenever $\bar{r}>n-\theta$.

Lemma 12 When $\theta>0$, the bubble-less steady state equilibrium is locally saddle-path stable.

- When $\bar{r}>n$, for a given $k_{0}$, there is a unique trajectory converging to the steady state. This trajectory is bubble-less.

- When $\bar{r}<n$, for a given $k_{0}$, there is a continuum of values of $q_{0}$ that are consistent with convergence to the steady state.

Recall that the bubble component grows at rate $f^{\prime}\left(k_{t}\right)-\delta-n$, which is approximately equal to $\bar{r}-n$ in the neighborhood of the steady state. Hence, when $\bar{r}>n$, any bubble must grow as it approaches the steady state. But the steady state is bubble-less. Hence, when $\bar{r}>n$, there cannot be a bubble along the trajectory converging to the steady state. Conversely, when $\bar{r}<n$, a bubble must shrink as it approaches the steady state. In that case, there is a continuum of bubbly trajectories, with the magnitude of bubbles becoming vanishingly small as the economy converges to the bubble-less steady state.

Putting all these results together yields the following proposition.

Proposition 1 Focusing on equilibrium paths that converge to a steady state, we have the following possibilities for any given value of $k_{0}$ :

When $\theta=0$ :

- There exists is a unique equilibrium. It is bubble-less and the interest rate converges to $r$, which satisfies $r>\max \{\bar{r}, n\}$.

When $\theta>0$ :

- If $\bar{r} \in(n, \infty)$, there exists a unique equilibrium. It is bubble-less and the interest rate converges to $\bar{r}$.

- If $\bar{r} \in(n-\theta, n)$, there exists two steady state equilibria: one bubbly with $r=n$; the other bubble-less with $r=\bar{r}$.

- There exists a unique value of $q_{0}$ such that the economy converges to the bubbly steady state. 
- There is a continuum of values of $q_{0}$ such that the economy converges to the bubble-less steady state. These equilibria are asymptotically bubble-less.

- If $\bar{r} \in(-\infty, n-\theta]$, there exists a unique equilibrium. It is bubbly and the interest rate converges to $n$.

Thus, bubbles can only occur when $\bar{r}<n$ and $\theta>0$. Tirole (1985) derived a similar result within an OLG economy for the special case where $\theta=n$. As discussed in the introduction, despite this similarity, the underlying mechanism generating the possibility of bubbles is fundamentally different under the two approaches. In the OLG economy, the bubble is a coordination device that transfers resources across cohorts, while in our economy the bubble is a store of value that allows the representative household to satisfy its preference for wealth.

When $\theta>0$ and $\bar{r} \in(n-\theta, n)$, there is a continuum of equilibrium values of $q_{0}$. While we cannot characterize them analytically, Figure 1 shows that these values satisfy $q_{0} \in\left[\mu_{0}, \hat{q}_{0}\right]$ where $\mu_{0}$ is the fundamental value of the asset. When $q_{0}=\hat{q}_{0}$, i.e. the highest feasible asset value, then the economy converges to the bubbly steady steady state (dashed line). For all $q_{0} \in\left[\mu_{0}, \hat{q}_{0}\right)$, the economy converges to the bubble-less steady state. In fact, when $q_{0}=\mu_{0}$, the asset is worth its fundamental value throughout (solide line); while, when $q_{0} \in\left(\mu_{0}, \hat{q}_{0}\right)$, the bubbly component is strictly positive but becomes arbitrarily small as the economy converges to the bubble-less steady state (dashed-dotted lines). This pattern has been verified for all our numerical simulations.

Proposition 1 relies on local stability results, which is why we have only characterized equilibria that converge to a steady state. In the special cases where $\theta=+\infty$, we can use a three dimensional phase diagram to rule out alternative equilibrium paths (since the $\dot{q}_{t}=0$ hyperplane is now time invariant). Figure 2 shows the main candidate trajectories. The solid lines correspond to equilibrium trajectories, while the dashed lines are trajectories that violate some equilibrium condition. The steady state equilibria are located at the intersection of the $\dot{c}_{t}=0, \dot{k}_{t}=0$, and $\dot{q}_{t}=0$ hyperplanes. Note that, when $\theta=+\infty$, we have $\dot{q}_{t}=\left(f^{\prime}\left(k_{t}\right)-\delta-n\right) q_{t}$. Thus, the $\dot{q}_{t}=0$ hyperplane has two components: $f^{\prime}\left(k_{t}\right)-\delta=n$ and $q_{t}=0$. The former corresponds to the bubbly steady state, the latter to the bubble-less steady state. The trajectories that do not converge to a steady state equilibrium must either end up with: (i) $k_{t}=0$ in finite time, which must violate the consumption Euler equation (28); or (ii) $k_{t}=\bar{k}$ where $\bar{k}$ is given by $f(\bar{k})+z=(\delta+n) \bar{k}$, which violates the transversality condition (as would be the case in the absence of infinitely-lived assets). ${ }^{16}$

\footnotetext{
${ }^{16}$ Note that Figure 2 is a three-dimensional equivalent to Figure 1 of Tirole (1985). Tirole does not need the consumption dimension since, in the Diamond model, aggregate consumption is a function of the capital stock and of the asset value.
} 


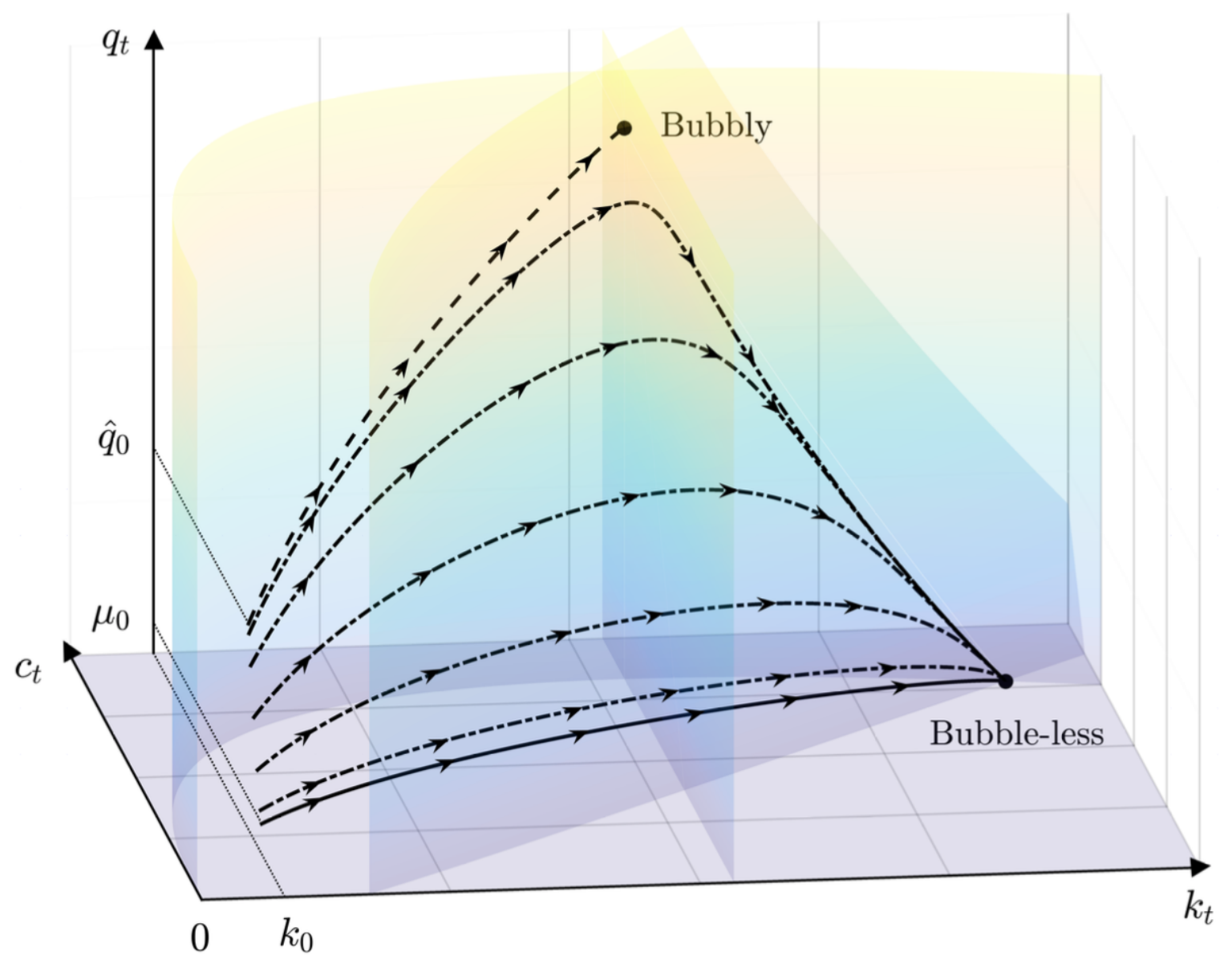

Figure 1: Equilibrium dynamics when $\theta>0$ and $\bar{r} \in(n-\theta, n)$.

A similar exercise could be performed when $\theta=0$. However, when $\theta \in(0,+\infty)$, the system of differential equation is not homogeneous and not autonomous, which prevents the construction of a simple three dimensional phase diagram. However, numerical simulations show that alternative equilibrium paths would also be ruled out in that case. Thus, for any $\theta \in[0,+\infty)$, all the equilibrium paths converge to one of the steady states of Proposition 1, which therefore are globally saddle-path stable.

So far, we have assumed a decreasing marginal utility of wealth. Note that, in the special case of a constant marginal utility of wealth, the dynamics of consumption and capital, given by (28) and (29), are independent of the asset price $q_{t}$. Thus, the economy converges to the bubble-less steady state, where $r=\bar{r}$. However, when $\bar{r} \leq n-\theta$, this cannot be an equilibrium (by Lemma 3). Hence, in that case, there is no equilibrium. ${ }^{17}$

\footnotetext{
${ }^{17}$ In this economy, under a downward price or wage rigidity, there could exist a secular stagnation equilibrium (Ono 2015, Michau 2018). If the frictionless neoclassical equilibrium does not exist, then the secular stagnation equilibrium can be the unique equilibrium of the economy. Interestingly, here the secular stagnation equilibrium could be made unique by the requirement that $\bar{r}>n-\theta$, while in Michau (2018) it could be made unique by an inflation ceiling that also imposes a lower bound on the real interest rate. See Schlegl (2018) for a careful analysis of secular stagnation in the $\theta=0$ case.
} 


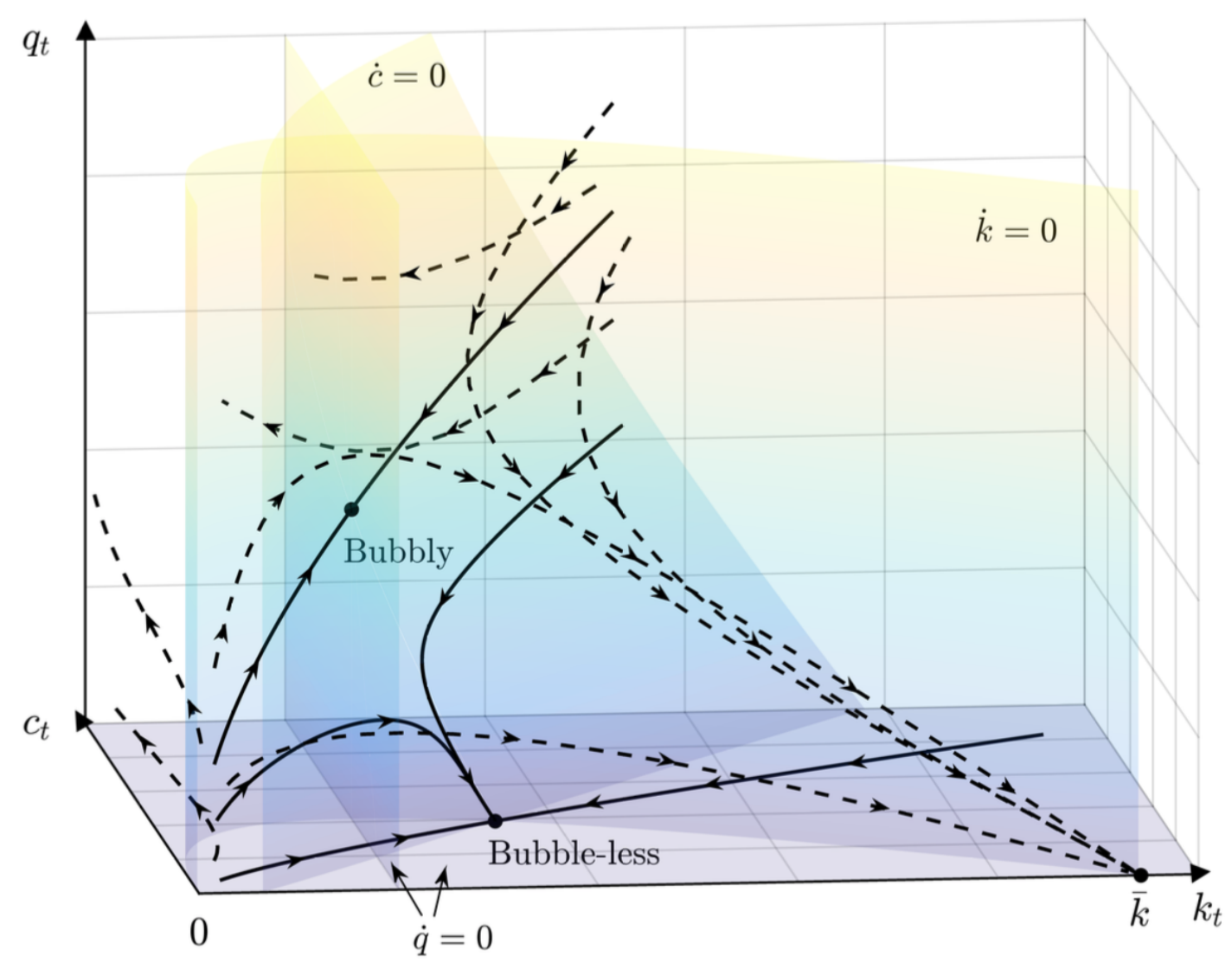

Figure 2: Phase diagram when $\theta=+\infty$ and $\bar{r}<n$.

Conversely, when $\bar{r}>n-\theta$, any positive bubble can be an equilibrium. ${ }^{18}$ When $\bar{r}>n$, these bubbles must be growing forever. This is sustainable as the insatiability of the preference for wealth implies that, in equilibrium, there is a zero marginal propensity to consume out of wealth.

\section{Government Debt}

Let us now return to the situation of Section 3, where there is no infinitely-lived real asset. Thus, the exogenous rents $z N_{t}$ can no longer be capitalized. However, we now introduce government debt.

The government makes an initial transfer of wealth $b_{0}>0$ to each individual. It is then subject to the standard debt accumulation equation:

$$
\dot{b}_{t}=\left(r_{t}-n\right) b_{t}-\tau_{t},
$$

\footnotetext{
${ }^{18}$ With a constant marginal utility of wealth, $r_{t}$ must eventually converge to $\bar{r}$. Thus, the fundamental value of the asset must either converge to a positive constant (when $\theta=0$ ) or to zero (when $\theta>0$ ), while the growth rate of the bubble component must converge to $\bar{r}-n$. But $\bar{r}<\rho$, which implies that the transversality condition (31) is always satisfied; even when $q_{t}$ tends to infinity.
} 
where $\tau_{t}$ denotes a lump-sum tax imposed on households at time $t$. Let $\varphi_{t}$ denote the present value of taxes from time $t$ onwards:

$$
\varphi_{t}=\int_{t}^{\infty} e^{-\int_{t}^{s}\left(r_{u}-n\right) d u} \tau_{s} d s
$$

Throughout our analysis, we treat the fiscal resources $\tau_{t}$, and therefore $\varphi_{t}$, as exogenously given. It is common to impose a no-Ponzi condition on government debt:

$$
\lim _{t \rightarrow \infty} e^{-\int_{0}^{t}\left(r_{s}-n\right) d s} b_{t} \leq 0
$$

It simply requires that, at any time $t$, the present value of lump-sum taxes is larger or equal to the current debt level. It can therefore equivalently be written as:

$$
b_{t} \leq \varphi_{t}
$$

However, we shall show that this condition is excessively restrictive. Indeed, the government's ability to borrow is only constrained by households' willingness to lend to it. This is determined by their transversality condition. To prove this result, we shall characterize the equilibrium of the economy without imposing the government's no-Ponzi condition and show that, in some cases, Ponzi schemes can be sustainable.

Note that, without a preference for wealth, the economy would converge to a steady state where $r_{t}=\rho$. In that case, the household's transversality condition entails that the household's no-Ponzi condition is binding. By Walras' law, this implies that the government's no-Ponzi condition is also binding. Without a preference for wealth, there is therefore no loss of generality in imposing the government's no-Ponzi condition.

Households consider that their wealth is equal to their asset holdings $a_{t}$ net of the present value of taxes $\varphi_{t}$. Indeed, if this was not the case, the government could artificially increase households' welfare by making a huge lump-sum payment that would subsequently be offset by a huge lump-sum tax. We therefore maintain that, from a welfare perspective, effective household wealth is equal to $a_{t}-\varphi_{t}$. The utility of the representative households is therefore given by:

$$
\int_{0}^{\infty} e^{-(\rho-n) t}\left[u\left(c_{t}\right)+\gamma\left(a_{t}-\varphi_{t}\right)\right] d t
$$

and its budget constraint by:

$$
\dot{a}_{t}=\left(r_{t}-n\right) a_{t}+w_{t}+z-\tau_{t}-c_{t},
$$

together with the no-Ponzi condition $\lim _{t \rightarrow \infty} e^{-\int_{0}^{t}\left(r_{s}-n\right) d s} a_{t} \geq 0$. 
Throughout our analysis, we assume that the government's no-Ponzi condition is either binding or violated, i.e. $b_{t} \geq \varphi_{t}$. In such cases, under the capital market clearing condition $a_{t}=k_{t}+b_{t}$, the household's no-Ponzi condition (6) must be satisfied. ${ }^{19}$ We can therefore omit the household's no-Ponzi condition from the set of equilibrium conditions.

The equilibrium of the economy $\left(c_{t}, k_{t}, b_{t}\right)_{t=0}^{\infty}$ is characterized by:

$$
\begin{gathered}
\frac{\dot{c}_{t}}{c_{t}}=\left[f^{\prime}\left(k_{t}\right)-\delta-\rho+\frac{\gamma^{\prime}\left(k_{t}+b_{t}-\varphi_{t}\right)}{u^{\prime}\left(c_{t}\right)}\right] \frac{u^{\prime}\left(c_{t}\right)}{-u^{\prime \prime}\left(c_{t}\right) c_{t}}, \\
\dot{k}_{t}=f\left(k_{t}\right)+z-c_{t}-(\delta+n) k_{t}, \\
\dot{b}_{t}=\left(f^{\prime}\left(k_{t}\right)-\delta-n\right) b_{t}-\tau_{t}, \\
\lim _{t \rightarrow \infty} e^{-(\rho-n) t} u^{\prime}\left(c_{t}\right)\left[k_{t}+b_{t}\right]=0
\end{gathered}
$$

$k_{0}$ given.

If the government chooses to satisfy its no-Ponzi condition, then $b_{t}=\varphi_{t}$. In that case, the Ricardian equivalence holds and fiscal policy cannot affect the equilibrium of the economy. The equilibrium paths of $c_{t}$ and $k_{t}$ are the same as in Section 3.

Can the government choose to violate its no-Ponzi condition? To answer this question, we need to determine the maximum sustainable level of government debt. Let $\tilde{b}_{t}=b_{t}-\varphi_{t}$ denote the magnitude of the Ponzi scheme at time $t$. The following lemma allows us to simplify our analysis.

Lemma 13 Any allocation $\left(c_{t}, k_{t}\right)_{t=0}^{\infty}$ that can be implemented under the fiscal policy $\left(\tau_{t}, b_{t}\right)_{t=0}^{\infty}$ can also be implemented under $\left(0, \tilde{b}_{t}\right)_{t=0}^{\infty}$, where $\tilde{b}_{t}=b_{t}-\varphi_{t}$.

Thus, without loss of generality, we could set $\tau_{t}=\varphi_{t}=0$ and replace $b_{t}$ by $\tilde{b}_{t}$. The resulting equations are identical to the ones that we had in the previous section in the special case where $\theta=\infty$. Government debt now plays the same role as the asset price in Section 4 . Why is government debt mathematically identical to an intrinsically worthless infinitely-lived asset? Government bonds are finitely lived, but they can be rolled over forever. Moreover, the (per capita) returns on such bonds are equal to $r_{t}-n$, which is the same as the returns to the bubble component of an infinitely-lived asset.

However, a crucial difference with the infinitely-lived asset is the choice of initial debt. Indeed, in Section 4 the initial price $q_{0}$ of an asset is determined by market forces, while here the initial level of government debt $b_{0}$ is, at least partly, determined by the government.

\footnotetext{
${ }^{19}$ The definition of $\varphi_{t}$, given by (46), implies that $\lim _{t \rightarrow \infty} e^{-\int_{0}^{t}\left(r_{s}-n\right) d s} \varphi_{t}=0$ (this is formally shown below in the proof of Lemma 13). Thus, $\lim _{t \rightarrow \infty} e^{-\int_{0}^{t}\left(r_{s}-n\right) d s} a_{t}=\lim _{t \rightarrow \infty} e^{-\int_{0}^{t}\left(r_{s}-n\right) d s}\left[k_{t}+\left(b_{t}-\varphi_{t}\right)+\right.$ $\left.\varphi_{t}\right] \geq 0$, since $k_{t} \geq 0$ and $b_{t} \geq \varphi_{t}$.
} 
Let $\bar{b}_{0}$ denote the initial transfer of wealth to households that the government intends to make. We assume that $\bar{b}_{0} \geq \varphi_{0}$. This transfer is financed by issuing a quantity $\bar{b}_{0}$ of government bonds. Importantly, only a level $\varphi_{0}$ of debt can be backed by fiscal resources. Let $b_{0}$ denote the amount of resources that households are willing to lend to the government, i.e. the quantity of bonds they are willing to buy. Note that, we cannot have $b_{0}<\varphi_{0}$, since the government never fails to raise debt backed by fiscal resources. We must therefore always have $b_{0} \in\left[\varphi_{0}, \bar{b}_{0}\right]$.

Let us focus on the interesting case where $\bar{b}_{0}>\varphi_{0}$, i.e. the government would like to run a Ponzi scheme. This naturally results in multiple equilibria. If $b_{0}<\bar{b}_{0}$, the government fails to sell the desired quantity of bonds. In that case, its initial transfer of wealth to households and its initial debt must both be equal to $b_{0}$, instead of $\bar{b}_{0}$. Indeed, not a single household is willing to lend beyond $b_{0}$ if it does not expect others to do so.

In fact, there is a continuum of equilibria indexed by $b_{0}$. If $b_{0}=\varphi_{0}$, then the equilibrium does not feature a Ponzi scheme; while, if $b_{0}>\varphi_{0}$, then it does. While the multiplicity of equilibria is similar to the case of the infinitely-lived asset, a key difference is that the government can reduce the range of equilibria through its choice of $\bar{b}_{0}$. However, the government cannot eliminate the equilibrium with no Ponzi scheme, i.e. the equilibrium with $b_{0}=\varphi_{0}$.

From Lemma 13, we can readily apply Proposition 1 with $\theta=+\infty$ to characterize the equilibria of the economy. We just need to consider that $\bar{b}_{0}$ is sufficiently high such as not to rule out any equilibrium.

Proposition 2 Focusing on equilibrium paths that converge to a steady state, we have the following possibilities for any given value of $k_{0}$ :

- If $\bar{r}>n$, there exists a unique equilibrium. The no-Ponzi condition must be binding, i.e. $b_{0}=\varphi_{0}$, and the interest rate converges to $\bar{r}$.

- If $\bar{r}<n$, there exists two steady state equilibria: one with a Ponzi scheme where $r=n$; the other without a Ponzi scheme where $r=\bar{r}$.

- There exists a unique value of $b_{0}>\varphi_{0}$ such that the economy converges to the steady state with a Ponzi scheme.

- There is a continuum of values of $b_{0}$ such that the economy converges to the steady state without a Ponzi scheme. While the no-Ponzi condition is satisfied in steady state, the government is running a Ponzi scheme whenever $b_{0}>\varphi_{0}$.

There cannot be a Ponzi scheme when $\bar{r}>n$ as $b_{t}$ would tend to infinity, which would be inconsistent with the equilibrium conditions (as shown by Lemma 2). Conversely, when 
the steady state capital stock without a Ponzi scheme is higher than under the golden rule, debt can be rolled over forever and a Ponzi scheme can therefore be sustainable.

When $\bar{r}<n$, there is a continuum of equilibrium values of $b_{0}$. They satisfy $b_{0} \in\left[\varphi_{0}, \hat{b}_{0}\right]$ for some constant $\hat{b}_{0}>\varphi_{0}$, where we implicitly assume that $\bar{b}_{0} \geq \hat{b}_{0}$. When $b_{0}=\hat{b}_{0}$, the economy converges to the steady state with a Ponzi scheme. When $b_{0} \in\left[\varphi_{0}, \hat{b}_{0}\right)$, the economy converges to the steady state where the no-Ponzi condition is binding. However, when $b_{0} \in\left(\varphi_{0}, \hat{b}_{0}\right)$, the no-Ponzi condition is violated, even though $b_{t}$ converges to $\varphi_{t}$. These possibilities could be seen on a three dimensional phase diagram.

With a constant marginal utility of wealth, there is no limit to government indebtedness. Indeed, in that case, the level of government debt does not affect the behavior of households. Hence, the initial transfer of wealth $b_{0}$ from the government to households can be arbitrarily large without altering the real allocation of resources in the economy.

The Ricardian equivalence states that, for a given present value of government expenditures (which are here normalized to zero), the timing of tax collection is neutral. Lemma 13 implies that, for a given initial transfer $b_{0}$ to households, two different tax policies $\left(\tau_{t}\right)_{t=0}^{\infty}$ that result in the same present value of taxes $\varphi_{0}$ implement the same allocation of resources. Hence, for a given value of $\tilde{b}_{0}$ and therefore a given path of $\tilde{b}_{t}=\tilde{b}_{0} e^{\int_{0}^{t}\left(r_{s}-n\right) d s}$, i.e. along a given equilibrium trajectory, the timing of tax collection does not matter. This immediately entails the following corollary.

\section{Corollary 1 Along any equilibrium trajectory, the Ricardian equivalence holds.}

Along any equilibrium trajectory, households expect a certain time path for the level of debt net of the present value of taxes and the government cannot be expected to deviate from it.

However, when $\bar{r}<n$, there exists a continuum of equilibrium trajectories. Can the government induce the economy to jump to a different equilibrium trajectory at time $t>0$ through a surprise change in the present value of taxes $\varphi_{t}$ ? The government can always raise $\varphi_{t}$, i.e. decrease the magnitude of its Ponzi scheme. However, the government can only decrease $\varphi_{t}$, i.e. increase the magnitude of its Ponzi scheme, if households expect the new policy to be sustainable over time. Once again, there are multiple equilibria due to the coordination of expectations across households. Of course, from an ex-ante perspective, once the economy is on a given equilibrium trajectory, a surprise change in $\varphi_{t}$ must be a zero probability event. ${ }^{20}$

\footnotetext{
${ }^{20}$ We are assuming here that the government is fully committed to the new fiscal policy, provided that it is feasible. This policy is therefore perceived as credible by households. Alternatively, if the government cannot credibly commit to a fiscal policy, then the equilibrium trajectory is determined by households' beliefs about future fiscal policy. Note that these beliefs can be affected by the government's fiscal policy announcements. Investigating the strategic interactions between government announcements and households' beliefs is beyond the scope of our analysis.
} 
The fact that our economy is consistent with the Ricardian equivalence is a fundamental difference with other models of rational bubbles (or Ponzi schemes). As we have seen in the introduction, in models based on the OLG structure or on financial frictions, bubbles exist to redistribute resources across people. Hence, the very existence of bubbles builds on the non-Ricardian nature of these models. Interestingly, this also implies that, in these models, the government can implement the bubbly allocation of resources through a lump-sum redistribution policy that mimics the bubble. For instance, in a dynamically inefficient OLG economy, the government can always implement the bubbly allocation by establishing a Pay As You GO (PAYGO) social security system. By contrast, in our economy, the government cannot implement the bubbly allocation through lump-sum transfers. ${ }^{21}$

If the government can roll over debt, why can't some households do the same? In theory, that's possible. However, infinitely-lived households are in fact dynasties. And, in practice, a fundamental constraint on the allocation of resources is that heirs cannot be forced to inherit debt. Thus, infinitely-lived dynasties cannot roll over debt forever. Only the government can do so! This justifies our assumption that households cannot violate their no-Ponzi condition.

\section{Money}

Let us now investigate the properties of a classical monetary economy with a preference for wealth. To generate a demand for money, we follow the money-in-the-utility-function approach à la Sidrauski (1967). This allows us to show that, despite apparent similarities, the preference for wealth is fundamentally different from money in the utility function.

We introduce a new financial asset, money, within the framework of the previous section. Money is a nominally risk-free asset that yields a zero nominal return. Let $M_{0}$ denote the initial supply of money in the economy. The money supply increases over time at rate $\omega_{t}$. The nominal quantity of money at any time $t$ is therefore given by:

$$
M_{t}=e^{\int_{0}^{t} \omega_{s} d s} M_{0}
$$

Let $P_{t}$ denote the price level at time $t$ and $\pi_{t}$ the inflation rate. Thus, the real supply of

\footnotetext{
${ }^{21}$ The government can rely on distortionary taxes to implement the capital stock and the consumption level of the bubbly steady state. However, the government cannot force the implementation of a Ponzi scheme and, without the corresponding increase in wealth, this policy would clearly reduce efficiency.
} 
money per capita $m_{t}$ is equal to:

$$
\begin{aligned}
m_{t} & =\frac{M_{t}}{P_{t} N_{t}}, \\
& =e^{\int_{0}^{t}\left(\omega_{s}-\pi_{s}-n\right) d s} \frac{M_{0}}{P_{0}} .
\end{aligned}
$$

Thus, the evolution of the money supply over time satisfies:

$$
\dot{m}_{t}=\left(\omega_{t}-\pi_{t}-n\right) m_{t}
$$

Newly supplied money is revenue to the government, whose real debt level therefore evolves according to:

$$
\dot{b}_{t}=\left(r_{t}-n\right) b_{t}-\tau_{t}-\omega_{t} m_{t} .
$$

Combining the previous two equations yields:

$$
\dot{b}_{t}+\dot{m}_{t}=\left(r_{t}-n\right)\left[b_{t}+m_{t}\right]-\tau_{t}-i_{t} m_{t}
$$

where $i_{t}$ denote the nominal interest rate, which is related to the real interest rate $r_{t}$ through the Fisher identity $i_{t}=r_{t}+\pi_{t}$.

By issuing money rather than bonds, the government economizes the nominal interest rate, which is the difference between the real returns $r_{t}$ on bonds and $-\pi_{t}$ on money. Thus, from a fiscal point of view, the nominal interest rate is a tax on households' money holdings. So, the present value of taxes $\varphi_{t}$ from $t$ onwards is now equal to:

$$
\varphi_{t}=\int_{t}^{\infty} e^{-\int_{t}^{s}\left(r_{u}-n\right) d u}\left(\tau_{s}+i_{s} m_{s}\right) d s
$$

If the government does not run a Ponzi scheme, then it must be able to redeem both its supply of bonds and of money. Thus, the government's no-Ponzi condition is given by:

$$
\lim _{t \rightarrow \infty} e^{-\int_{0}^{t}\left(r_{s}-n\right) d s}\left(b_{t}+m_{t}\right) \leq 0
$$

or, equivalently, by:

$$
b_{t}+m_{t} \leq \varphi_{t}
$$

This implies that the magnitude of a Ponzi scheme is now equal to:

$$
\tilde{b}_{t}=b_{t}+m_{t}-\varphi_{t}
$$

By the government liability accumulation equation (60) and the definition of the present 
value of taxes (61), we have:

$$
\dot{\tilde{b}}_{t}=\left(r_{t}-n\right) \tilde{b}_{t},
$$

regardless of monetary and fiscal policy. As in the previous section, we focus on cases where the government's no Ponzi condition is either binding or violated, i.e. $\tilde{b}_{t} \geq 0$.

Real household wealth per capita is now given by:

$$
a_{t}=k_{t}+b_{t}+m_{t}
$$

where $m_{t}$ denotes the real money balances per capita. We have:

$$
\dot{a}_{t}=\left(r_{t}-n\right) a_{t}-i_{t} m_{t}+w_{t}+z-\tau_{t}-c_{t},
$$

where $i_{t} m_{t}$ is the real opportunity cost of holding money rather than bonds or capital.

We now introduce money in the utility function by assuming that the representative household derives utility $h\left(m_{t}\right)$ from holding real money balances $m_{t}$, with $h^{\prime}(\cdot)>0$, $h^{\prime \prime}(\cdot)<0, \lim _{m \rightarrow 0} h^{\prime}(m)=\infty$, and $h^{\prime}(m)=0$ for all $m \geq \bar{m}$. At $\bar{m}$, the household is satiated with real money balances and does not derive any utility from holding more money for transaction purposes. The household's intertemporal utility function is therefore given by:

$$
\int_{0}^{\infty} e^{-(\rho-n) t}\left[u\left(c_{t}\right)+h\left(m_{t}\right)+\gamma\left(a_{t}-\varphi_{t}\right)\right] d t .
$$

The utility from real money balances $h\left(m_{t}\right)$ corresponds to a preference for liquidity, which is conceptually different from the preference for wealth $\gamma\left(a_{t}-\varphi_{t}\right)$.

The household's wealth net of the present value of taxes is equal to $a_{t}-\varphi_{t}=k_{t}+b_{t}+$ $m_{t}-\varphi_{t}=k_{t}+\tilde{b}_{t}$. Thus, $\tilde{b}_{t}$ measures the extent to which government assets $b_{t}+m_{t}$ net of the present value of taxes $\varphi_{t}$ represent a source of wealth for the representative household. If the government's no-Ponzi condition holds, then $\tilde{b}_{t}=0$ and the household's net wealth is simply equal to $k_{t}$. If the government runs a Ponzi scheme, then the household's net wealth rises to $k_{t}+\tilde{b}_{t} \cdot{ }^{22}$

The solution to the household's problem is characterized by the same equations as before, i.e. the consumption Euler equation (8) and the transversality (9) condition, together with a money demand equation:

$$
h^{\prime}\left(m_{t}\right)=i_{t} u^{\prime}\left(c_{t}\right) .
$$

\footnotetext{
${ }^{22}$ Note that the household's present value of taxes $\varphi_{t}$ is a function of its money holdings $m_{t}$. However, we assume that the representative household takes its net wealth from government assets $\tilde{b}_{t}$ as given. In other words, the household determines its money demand independently of its effect on $\tilde{b}_{t}$. While we can solve the alternative case, where the household reduces its future money holdings such as to feel wealthier today, it seems behaviorally implausible to us.
} 
Note that this money demand equation trivially implies that the nominal interest rate $i_{t}$ cannot be negative, which is the zero lower bound.

The household's transversality condition can be written as $\lim _{t \rightarrow \infty} e^{-(\rho-n) t} u^{\prime}\left(c_{t}\right)\left[k_{t}+\right.$ $\left.\tilde{b}_{t}+\varphi_{t}\right]=0$. If $\varphi_{t}$ is finite, which must be the case in equilibrium, we must have $\lim _{t \rightarrow \infty} e^{-\int_{0}^{t}\left(r_{u}-n\right) d u} \varphi_{t}=0$ and therefore $\lim _{t \rightarrow \infty} e^{-(\rho-n) t} u^{\prime}\left(c_{t}\right) \varphi_{t}=0 .^{23}$

The real equilibrium of the economy is characterized by:

$$
\begin{gathered}
\frac{\dot{c}_{t}}{c_{t}}=\left[f^{\prime}\left(k_{t}\right)-\delta-\rho+\frac{\gamma^{\prime}\left(k_{t}+\tilde{b}_{t}\right)}{u^{\prime}\left(c_{t}\right)}\right] \frac{u^{\prime}\left(c_{t}\right)}{-u^{\prime \prime}\left(c_{t}\right) c_{t}}, \\
\dot{k}_{t}=f\left(k_{t}\right)+z-c_{t}-(\delta+n) k_{t}, \\
\dot{\tilde{b}}_{t}=\left(f^{\prime}\left(k_{t}\right)-\delta-n\right) \tilde{b}_{t}, \\
\lim _{t \rightarrow \infty} e^{-(\rho-n) t} u^{\prime}\left(c_{t}\right)\left[k_{t}+\tilde{b}_{t}\right]=0, \\
k_{0} \text { given. }
\end{gathered}
$$

It immediately follows that the real equilibria of the economy, and hence the possibility of Ponzi schemes, are still characterized by Proposition 2 from the previous section. The presence of money does not affect the equilibrium structure of the economy, regardless of the actual choice of monetary and fiscal policy.

The government can only affect the equilibrium of the economy though its choice of the maximum magnitude of the Ponzi scheme, which we have denoted $\bar{b}_{0}$ in the previous section. In equilibrium, the government is assumed to be committed to a Ponzi scheme of a given magnitude $\tilde{b}_{t}=\tilde{b}_{0} e^{\int_{0}^{t}\left(r_{s}-n\right) d s}$, with $b_{0} \in\left[0, \bar{b}_{0}\right]$, that households believe to be sustainable over time. ${ }^{24}$ It is therefore natural to consider that lump-sum taxes $\tau_{t}$ are set such that, for any path of real money holdings $m_{t}$, the magnitude of the Ponzi scheme remains unchanged. ${ }^{25}$ This implies that money is completely neutral. The path of real money holdings $m_{t}$ is jointly determined by the money supply equation $\dot{m}_{t}=$ $\left(\omega_{t}-\pi_{t}-n\right) m_{t}$ and by the money demand equation $h^{\prime}\left(m_{t}\right)=\left[f^{\prime}\left(k_{t}\right)-\delta+\pi_{t}\right] u^{\prime}\left(c_{t}\right)$. Substituting the latter into the former yields:

$$
\dot{m}_{t}=\left(\omega_{t}-n+f^{\prime}\left(k_{t}\right)-\delta-\frac{h^{\prime}\left(m_{t}\right)}{u^{\prime}\left(c_{t}\right)}\right) m_{t}
$$

Any path of real money holdings is feasible, provided that $m_{t}$ remains positive. This includes speculative deflation, where $m_{t}$ tends to infinity, which is not ruled out by the

\footnotetext{
${ }^{23}$ Formally, this is shown in the proof of Lemma 13.

${ }^{24}$ If $b_{0}<\bar{b}_{0}$, then the Ponzi scheme of magnitude $\bar{b}_{0}$ was not necessarily perceived as sustainable by households.

${ }^{25}$ Alternatively, we could consider that, given the monetary and fiscal policy $\left(\tau_{t}, \omega_{t}\right)_{t=0}^{\infty}$, the Ponzi scheme can only be of the equilibrium magnitude for a unique feasible path of $m_{t}$. In that case, all other feasible paths of $m_{t}$ are ruled out by this equilibrium.
} 
household's transversality condition since money is effectively redeemed by fiscal policy.

Alternatively, we can consider that the government sets the lump-sum tax $\tau_{t}$ such that $b_{t}$ is equal to zero at all times. This policy implies $b_{0}=0$ and $\tau_{t}=-\omega_{t} m_{t}$, i.e. the revenue from money creation is redistributed lump-sum to households. The government effectively implements helicopter drops of money, which are negative whenever $\omega_{t}<0$. Money is therefore the only asset issued by the government, which corresponds to an important benchmark of the literature in monetary economics.

In the remainder of this section, we investigate the equilibrium possibilities under helicopter drops of money, assuming a constant growth rate $\omega$ of the money supply. We first need to compute the magnitude $\tilde{b}_{t}$ of the Ponzi scheme as a function of the money growth rate $\omega$.

Lemma 14 Under helicopter drops of money, i.e. $b_{0}=0$ and $\tau_{t}=-\omega_{t} m_{t}$, the magnitude of the Ponzi scheme is given by:

$$
\tilde{b}_{t}=m_{t}-\varphi_{t}=\left\{\begin{array}{ll}
\infty & \text { if } \omega>\lim _{t \rightarrow \infty} i_{t} \\
m_{t} e^{\int_{t}^{\infty}\left(\omega-i_{u}\right) d u} & \text { if } \omega=\lim _{t \rightarrow \infty} i_{t} \\
0 & \text { if } \omega<\lim _{t \rightarrow \infty} i_{t}
\end{array} .\right.
$$

Recall that taxes on real money balances are equal to $i_{t} m_{t}$, while lump-sum transfers to households amount to $\omega m_{t}$. Thus, if $\omega>\lim _{t \rightarrow \infty} i_{t}$, then transfers are asymptotically larger than taxes, resulting in an infinitely large Ponzi scheme. Conversely, if $\omega<\lim _{t \rightarrow \infty} i_{t}$, transfers are asymptotically lower than taxes, implying that the government eventually redeems the money supply, which entails $\varphi_{t}=m_{t}$ and $\tilde{b}_{t}=0$. Finally, in a steady state equilibrium where $\omega=i$, taxes and transfers are equally large resulting in a zero present value of taxes and, hence, in a Ponzi scheme equal to the outstanding stock of real money balances.

Clearly, the magnitude of the Ponzi scheme must be consistent with the real equilibrium structure of the economy. For instance, we cannot have an equilibrium with an infinitely large Ponzi scheme, which rules out any equilibrium with $\omega>\lim _{t \rightarrow \infty} i_{t}$. We therefore need to investigate how the real and the nominal sides of the economy are related to each other.

On the real side, the equilibrium paths of $c_{t}, k_{t}$, and $\tilde{b}_{t}$ are still determined by Proposition 2. The economy must either converge to the no-Ponzi steady state characterized by $\tilde{b}=0$ and $r=\bar{r}$ or to the Ponzi steady state with $\tilde{b}>0$ and $r=n$. For simplicity, we now consider that the real economy is in steady state. However, this does not impose any constraint on the nominal variables $m_{t}, i_{t}$, and $\pi_{t}$.

The following proposition gives the equilibrium possibilities under helicopter drops of money, assuming that the real economy is in steady state. 
Proposition 3 Under helicopter drops of money, i.e. $b_{0}=0$ and $\tau_{t}=-\omega_{t} m_{t}$ :

- The Ponzi steady state with $\tilde{b}>0$ and $r=n$ can only arise if $\bar{r}<n$ and $\omega=$ $h^{\prime}(\tilde{b}) / u^{\prime}(c)$ where $\tilde{b}$ is the solution to $\gamma^{\prime}(k+\tilde{b})=(\rho-n) u^{\prime}(c)$. In that case, $m_{t}=$ $\tilde{b}>0$.

- The no-Ponzi steady state with $\tilde{b}=0$ and $r=\bar{r}$ can arise under the following circumstances, where $m$ is defined by $h^{\prime}(m)=[\omega+\bar{r}-n] u^{\prime}(c)$ whenever $\omega \geq$ $-(\bar{r}-n)$ :

- Constant real money balances (i.e. $m_{t}=m$ for all $t$ ) if and only if $\bar{r}>n$ and $\omega \geq-(\bar{r}-n)$

- Speculative hyperinflation (i.e. $m_{0}<m$, with $m=\infty$ if $\omega<-(\bar{r}-n)$, and $\left.\lim _{t \rightarrow \infty} m_{t}=0\right)$ if and only if $\lim _{x \rightarrow 0+} x h^{\prime}(x)=0$;

- Speculative deflation (i.e. $m_{0}>m$ and $\lim _{t \rightarrow \infty} m_{t}=\infty$ ) if and only if $\bar{r}>n$ and $\omega \in[-(\bar{r}-n), 0)$.

By lemma 14, the Ponzi steady state can only arise with $m_{t}=\tilde{b}>0$ and $\omega=$ $i=h^{\prime}(\tilde{b}) / u^{\prime}(c)$. There is therefore a unique growth rate of the money supply consistent with the Ponzi steady state. Intuitively, the real side of the economy determines the equilibrium magnitude of the Ponzi scheme, equal to $\tilde{b}$, while money demand determines the corresponding nominal interest rate, equal to $h^{\prime}(\tilde{b}) / u^{\prime}(c)$, and therefore the required money growth rate $\omega$.

Under the no-Ponzi steady state, the magnitude $\tilde{b}$ of the Ponzi scheme must be equal to zero. By Lemma 14, this requires $\lim _{t \rightarrow \infty} h^{\prime}\left(m_{t}\right) / u^{\prime}(c)=\lim _{t \rightarrow \infty} i_{t}>\omega$. On the nominal side, three different types of equilibria can be consistent with the no-Ponzi steady state.

First, there is a nominal steady state, where real money balances are constant over time. By the money supply equation (58), inflation must be equal to $\omega-n$. This steady state can only exist if the corresponding nominal interest rate is positive, i.e. if $i=\bar{r}+\pi=\bar{r}+\omega-n \geq 0$. Also, the condition $\lim _{t \rightarrow \infty} i_{t}>\omega$ simplifies to $\bar{r}>n$.

Second, there is a speculative hyperinflation equilibrium, where real money balances monotonically converge to zero and the nominal interest rate to infinity. The requirement $\lim _{t \rightarrow \infty} i_{t}>\omega$ is therefore trivially satisfied. The only other requirement is that real money balances must remain positive. By the dynamic equation for real money balances (75), this requires $\lim _{x \rightarrow 0+} x h^{\prime}(x)=0$ as, otherwise, $m_{t}=0$ would imply $\dot{m}_{t}<0$.

Finally, there is the possibility of speculative deflation, where real money balances diverge to infinity and the nominal interest rate reaches the zero lower bound as soon as $m_{t} \geq \bar{m}$. First, this requires the initial real money balances to be higher than in the nominal steady state, i.e. $m_{0}>m$. The steady state value $m$ must therefore be finite, 
i.e. $\omega \geq-(\bar{r}-n)$. Also, the condition $\lim _{t \rightarrow \infty} i_{t}>\omega$ simplifies to $\omega<0$. Obviously, the two requirements, $\omega<0$ and $\omega \geq-(\bar{r}-n)$, can only be jointly satisfied when $\bar{r}>n$.

Interestingly, we know that in a classical monetary economy, speculative inflation requires $\lim _{x \rightarrow 0+} x h^{\prime}(x)=0$ (Obstfeld and Rogoff 1983), while speculative deflation requires $\omega<0$ (Brock 1975; Buiter and Sibert 2007). Hence, in the absence of Ponzi schemes, the preference for wealth preserves the usual properties of monetary economies. This should not be surprising as the classical monetary economy of the literature corresponds to the special case where the preference for wealth is always equal to zero.

We have a dichotomy between the real side of the economy, where the preference for wealth is responsible for the possibility of Ponzi schemes, and the nominal side, where money-in-the-utility-function determines the dynamics of real money balances and of other nominal variables. This shows that, despite apparent similarities, the preference for wealth and money-in-the-utility-function are fundamentally of a different nature.

Nonetheless, when money is the only financial asset supplied by the government, the size of the money-Ponzi scheme must be consistent with the real equilibrium of the economy. Hence, helicopter drops of money can restrict the range of equilibrium possibilities. In particular, there is a unique growth rate of the money supply consistent with the Ponzi steady state. But, importantly, any real allocation of resources that can be implemented under helicopter drops of money can also be implemented under an appropriate fiscal policy.

\section{Conclusion}

In this paper, we have shown that rational bubbles can exist in a frictionless neoclassical economy, provided that infinitely-lived households have a preference for wealth. Hence, an OLG structure or financial frictions are not necessary for the existence of rational bubbles. Not only does this finding broadens the scope for rational bubbles, it also provides a convenient micro-foundation to introduce bubbles within a representative agent economy.

Turning to public debt, we have shown that Ponzi schemes can be sustainable under the same circumstances that make bubbles possible. Hence, in general, the sustainability of public debt is not determined by the no-Ponzi condition but, instead, by the representative household's transversality condition. Also, we have reconciled the existence of rational bubbles with the Ricardian equivalence.

All these insights survive in a monetary economy, where the preference for wealth only affects the real side of the economy, while money-in-the-utility-function only affects the nominal side. However, when money is the only financial asset supplied by the government, the growth rate of the nominal money supply severely limits the scope for 
Ponzi schemes.

Bubbles are particularly likely to occur in environments with persistently low interest rates. This exactly corresponds to the type of circumstances where the economy could also suffer from seculars stagnation, i.e. from a persistent lack of demand. ${ }^{26}$ As shown by Ono (2015) and Michau (2018), introducing money and a downward wage rigidity within our framework would be sufficient to obtain a secular stagnation equilibrium. In further research, we therefore intend to investigate the interaction between secular stagnation, rational bubbles, and Ponzi schemes.

\section{References}

[1] Abel, A.A., Mankiw, N.G., Summers, L.H. and Zeckhauser, R.J. (1989), 'Assessing Dynamic Efficiency: Theory and Evidence', Review of Economic Studies, 56(1), 1-19.

[2] Acemoglu, D. (2009), Introduction to Modern Economic Growth, Princeton: Princeton University Press.

[3] Airaudo, M. (2017), 'Complex Stock Price Dynamics under Max Weber's Spirit of Capitalism Hypothesis', Economic Theory, 64, 47-73.

[4] Allen, F., Barlevy, G. and Gale, D. (2017), 'On Interest Rate Policy and Asset Bubbles', working paper, Imperial College, Chicago Fed, and NYU.

[5] Aoki, K., Nakajima, T. and Nikolov, K. (2014), 'Safe Asset Shortages and Asset Price Bubbles', Journal of Mathematical Economics, 53, 164-174.

[6] Asriyan, V., Fornaro, L., Martin, A. and Ventura, J. (2016), 'Monetary Policy for a Bubbly World', working paper, CREI.

[7] Azariadis, C. and Smith, B.D. (1993), 'Adverse Selection in the Overlapping Generations Model: The Case of Pure Exchange', Journal of Economic Theory, 60, 277-305.

[8] Bakshi, G.S. and Chen, Z. (1996), 'The Spirit of Capitalism and Stock-Market Prices', American Economic Review, 86(1), 133-157.

[9] Benhabib, J., Bisin, A. and Luo, M. (2017), 'Wealth Distribution and Social Mobility in the US: A Quantitative Approach', working paper, NYU.

\footnotetext{
${ }^{26}$ So far, we only know of three market structures that can generate demand-driven secular stagnation: the OLG structure (Kocherlakota 2013; Eggertsson, Mehrotra and Robbins 2017), credit constraints (Kocherlakota 2013), and the preference for wealth (Ono 2015; Michau 2018). Interestingly, these three structures are consistent with rational bubbles.
} 
[10] Biswas, S., Hanson, A. and Phan, T. (2017), 'Bubbly Recessions', working paper, University of North Carolina at Chapel Hill.

[11] Blanchard, O.J. (1985), 'Debt, Deficits, and Finite Horizons', Journal of Political Economy, 93(2), 223-247.

[12] Brock, W.A. (1975), 'A Simple Perfect Foresight Monetary Model', Journal of Monetary Economics, 1, 133-150.

[13] Buiter, W.H. and Sibert, A.C. (2007), 'Deflationary Bubbles', Macroeconomic Dynamics, 11, 431-454.

[14] Cagetti, M. and De Nardi, M. (2006), 'Entrepreneurship, Frictions, and Wealth', Journal of Political Economy, 114(5), 835-870.

[15] Carroll, C.D. (2000), 'Why Do the Rich Save So Much?', in Does Atlas Shrug? The Economic Consequences of Taxing the Rich, edited by Joel B. Slemrod, Cambridge, MA: Harvard University Press.

[16] De Nardi, M. (2004), 'Wealth Inequality and Intergenerational Links', Review of Economic Studies, 71, 743-768.

[17] Diamond, P.A. (1965), 'National Debt in a Neoclassical Growth Model', American Economic Review, 55(5), 1126-1150.

[18] Dong, F., Miao, J. and Wang, P. (2017), 'Asset Bubbles and Monetary Policy', working paper, Shanghai Jiao Tong University, Boston University, and Hong Kong University of Science and Technology.

[19] Dynan, K.E., Skinner, J. and Zeldes, S.P. (2004), 'Do the Rich Save More?', Journal of Political Economy, 112(2), 397-444.

[20] Eggertsson, G.B., Mehrotra, N.R., and Robbins, J.A. (2017), 'A Model of Secular Stagnation: Theory and Quantitative Evaluation', working paper, Brown University.

[21] Farhi, E. and Tirole, J. (2012), 'Bubbly Liquidity', Review of Economic Studies, 79, 678-706.

[22] Gali, J. (2014), 'Monetary Policy and Rational Asset Price Bubbles', American Economic Review, 104(3), 721-752.

[23] Gali, J. (2017), 'Monetary Policy and Bubbles in a New Keynesian Model with Overlapping Generations', working paper, CREI.

[24] Geerolf, F. (2017), 'Reassessing Dynamic Efficiency', working paper, UCLA. 
[25] Grossman, G.M. and Yanagawa, N. (1993), 'Asset Bubbles and Endogenous Growth', Journal of Monetary Economics, 31, 3-19.

[26] Hanson, A. and Phan, T. (2017), 'Bubbles, Wage Rigidity, and Persistent Slumps', Economic Letters, 151, 66-70.

[27] Hellwig, C. and Lorenzoni, G. (2009), 'Bubbles and Self-Enforcing Debt', Econometrica, 77(4), 1137-1164.

[28] Hirano, T. and Yanagawa, N. (2017), 'Asset Bubbles, Endogenous Growth, and Financial Frictions', Review of Economic Studies, 84, 406-443.

[29] Ikeda, D. (2017), 'Monetary Policy, Inflation and Rational Asset Price Bubbles', working paper, Bank of England.

[30] Kamihigashi, T. (2008), 'The Spirit of Capitalism, Stock Market Bubbles and Output Fluctuations', International Journal of Economic Theory, 4, 3-28.

[31] King, I. and Ferguson, D. (1993), 'Dynamic Inefficiency, Endogenous Growth, and Ponzi Games', Journal of Monetary Economics, 32, 79-104.

[32] Kocherlakota, N.R. (1992), 'Bubbles and Constraints on Debt Accumulation', Journal of Economic Theory, 57, 245-256.

[33] Kocherlakota, N.R. (2008), 'Injecting Rational Bubbles', Journal of Economic Theory, $142,218-232$.

[34] Kocherlakota, N. (2013), 'Impact of Land Price Fall When Labor Markets are Incomplete', working paper, Federal Reserve Bank of Minneapolis.

[35] Kopczuk, W. (2009), 'Economics of Estate Taxation: A Brief Review of Theory and Evidence', Tax Law Review, 63(1), 139-157.

[36] Kumhof, M., Rancière, R. and Winant, P. (2015), 'Inequality, Leverage, and Crises', American Economic Review, 105(3), 1217-1245.

[37] Marshall, A. (1890), Principles of Economics, London: MacMillan Press.

[38] Martin, A. and Ventura, J. (2012), 'Economic Growth with Bubbles', American Economic Review, 102(6), 3033-3058.

[39] Miao, J. (2016), 'Introduction to Economic Theory of Bubbles II', Journal of Mathematical Economics, 65, 139-140. 
[40] Miao, J. and Wang, P. (2014), 'Sectoral Bubbles, Misallocation, and Endogenous Growth', Journal of Mathematical Economics, 53, 153-163.

[41] Miao, J. and Wang, P. (2017), 'Asset Bubbles and Credit Constraints', American Economic Review, forthcoming.

[42] Michaillat, P. and Saez, E. (2015), 'An Economical Business-Cycle Model', working paper, UC Berkeley and LSE.

[43] Michaillat, P. and Saez, E. (2018), 'A New Keynesian Model with Wealth in the Utility Function', working paper, UC Berkeley and Brown University.

[44] Michau, J.B. (2018), 'Secular Stagnation: Theory and Remedies', Journal of Economic Theory, forthcoming.

[45] Obstfeld, M. and Rogoff, K. (1983), 'Speculative Hyperinflations in Maximizing Models: Can We Rule Them Out?', Journal of Political Economy, 91(4), 675-687.

[46] O'Connell, S.A. and Zeldes, S.P. (1988), 'Rational Ponzi Games', International Economic Review, 29(3), 431-450.

[47] Ono, Y. (1994), Money, Interest, and Stagnation: Dynamic Theory and Keynes's Economics, Oxford: Oxford University Press.

[48] Ono, Y. (2001), 'A Reinterpretation of Chapter 17 of Keynes's General Theory: Effective Demand Shortage under Dynamic Optimization', International Economic Review, 42(1), 207-236.

[49] Ono, Y. (2015), 'Growth, Secular Stagnation and Wealth Preference', ISER Discussion Paper No. 946, Osaka University.

[50] Ono, Y. and Yamada, K. (2018), 'Difference or Ratio: Implications of Status Preference on Stagnation', Australian Economic Papers, forthcoming.

[51] Piketty, T. (2011), 'On the Long-Run Evolution of Inheritance: France 1820-2050', Quarterly Journal of Economics, 126(3), 1071-1131.

[52] Saez, E. and Stantcheva, S. (2018), 'A Simpler Theory of Optimal Capital Taxation', Journal of Public Economics, 162, 120-142.

[53] Saint-Paul, G. (1992), 'Fiscal Policy in an Endogenous Growth Model', Quarterly Journal of Economics, 107(4), 1243-1259.

[54] Santos, M.S. and Woodford, M. (1997), 'Rational Asset Pricing Bubbles', Econometrica, 65(1), 19-57. 
[55] Samuelson, P.A. (1958), 'An Exact Consumption-Loan Model of Interest with or without the Social Contrivance of Money', Journal of Political Economy, 66(6), 467482 .

[56] Scheinkman, J.A. and Weiss, L. (1986), 'Borrowing Constraints and Aggregate Economic Activity', Econometrica, 54(1), 23-45.

[57] Schlegl, M. (2018), 'Secular Stagnation in an Economy with Land', ISER Discussion Paper No. 1032, Osaka University.

[58] Shell, K. (1971), 'Notes on the Economics of Infinity', Journal of Political Economy, 79(5), 1002-1011.

[59] Sidrauski, M. (1967), 'Rational Choice and Patterns of Growth in a Monetary Economy', American Economic Review, 57(2), 534-544.

[60] Steedman, I. (1981), 'Time Preference, The Rate of Interest and Abstinence from Accumulation', Australian Economic Papers, 20(37), 219-234.

[61] Straub, L. (2018), 'Consumption, Savings, and the Distribution of Permanent Income', working paper, MIT.

[62] Tirole, J. (1982), 'On the Possibility of Speculation under Rational Expectations', Econometrica, 50(5), 1163-1181.

[63] Tirole, J. (1985), 'Asset Bubbles and Overlapping Generations', Econometrica, 53(6), 1499-1528.

[64] Wallace, N. (1980), 'The Overlapping Generation Models of Fiat Money', in Models of Monetary Economics, edited by John H. Kareken and Neil Wallace, Minneapolis: Federal Reserve Bank of Minneapolis.

[65] Weil, P. (1989), 'Overlapping Families of Infinitely-Lived Agents', Journal of Public Economics, 38, 183-198.

[66] Woodford, M. (1980), 'Public Debt as Private Liquidity', American Economic Review, 80(2), 382-388.

[67] Yaari, M.E. (1965), 'Uncertain Lifetime, Life Insurance, and the Theory of the Consumer', Review of Economic Studies, 32(2), 137-150.

[68] Zhou, G. (2016), 'The Spirit of Capitalism and Rational Bubbles', Macroeconomic Dynamics, 20(6), 1432-1457.

[69] Zou, H.F. (1994), "The Spirit of Capitalism" and Long-Run Growth', European Journal of Political Economy, 10, 279-293. 


\section{A Proof of Lemma 1}

The steady state equilibrium is jointly characterized by equations (20) and (21). The first of these two equations can be written as:

$$
u^{\prime}(c)=\frac{\gamma^{\prime}(k)}{\rho+\delta-f^{\prime}(k)}
$$

Let $\tilde{k}$ be defined as $f^{\prime}(\tilde{k})-\delta=\rho$. Thus, this equation defines $c$ as a continuous and strictly increasing function of $k$ for all $k \in(\tilde{k},+\infty)$. Also, $c$ tends to 0 as $k$ tends to $\tilde{k}$ from above. Let us call the resulting function $c_{1}$.

Let $\hat{k}$ and $k^{*}$ be defined as $f(\hat{k})+z=(\delta+n) \hat{k}$ and $f^{\prime}\left(k^{*}\right)=\delta+n$, respectively. The other equilibrium relationship, (21), defines $c$ as a continuous function of $k$, which is increasing on $\left[0, k^{*}\right)$ and decreasing on $\left(k^{*}, \hat{k}\right]$. Also, $c$ is equal to 0 when $k$ is equal to $\hat{k}$. Let us call this function $c_{2}$.

Note that $f^{\prime}\left(k^{*}\right)-\delta=n<\rho=f^{\prime}(\tilde{k})-\delta$, which implies that $\tilde{k}<k^{*}$. Also, by definition of $\hat{k}$ and $k^{*}$, we trivially have $f^{\prime}(\hat{k})<\delta+n=f^{\prime}\left(k^{*}\right)$. Thus, $\tilde{k}<k^{*}<\hat{k}$. We have shown that $c_{1}$ is continuous and increasing on $(\tilde{k},+\infty)$ with $\lim _{k \rightarrow \tilde{k}+} c_{1}(k)=0$ and $c_{2}$ is positive and continuous on $[0, \hat{k}]$ with $c_{2}(\hat{k})=0$. An equilibrium must therefore exist on $(\tilde{k}, \hat{k})$.

Uniqueness of the equilibrium requires the slope of $c_{1}$ to exceed the slope of $c_{2}$ at each intersection of both lines in the $k-c$ diagram. We have:

$$
\begin{aligned}
\frac{\partial c_{1}}{\partial k}-\frac{\partial c_{2}}{\partial k} & =\frac{\gamma^{\prime \prime}(k)}{u^{\prime \prime}(c)\left[\rho+\delta-f^{\prime}(k)\right]}+\frac{f^{\prime \prime}(k) \gamma^{\prime}(k)}{u^{\prime \prime}(c)\left[\rho+\delta-f^{\prime}(k)\right]^{2}}-\left[f^{\prime}(k)-\delta-n\right] \\
& =\frac{\gamma^{\prime \prime}(k)}{u^{\prime \prime}(c)} \frac{u^{\prime}(c)}{\gamma^{\prime}(k)}+\frac{f^{\prime \prime}(k)\left[u^{\prime}(c)\right]^{2}}{u^{\prime \prime}(c) \gamma^{\prime}(k)}-\left[f^{\prime}(k)-\delta-n\right], \\
& =\frac{-\gamma^{\prime \prime}(k)}{u^{\prime \prime}(c)} \frac{u^{\prime}(c)}{\gamma^{\prime}(k)}\left[-1-\frac{f^{\prime \prime}(k) u^{\prime}(c)}{\gamma^{\prime \prime}(k)}+\frac{u^{\prime \prime}(c)}{\gamma^{\prime \prime}(k)} \frac{\gamma^{\prime}(k)}{u^{\prime}(c)}\left[f^{\prime}(k)-\delta-n\right]\right]
\end{aligned}
$$

From Assumption 1, we can compute $d \alpha / d k$ for $\alpha=0$. It exactly corresponds to the term in bracket, and we know by Assumption 1 that it must be strictly negative. We must therefore have:

$$
\frac{\partial c_{1}}{\partial k}-\frac{\partial c_{2}}{\partial k}>0
$$

for all $k$ such that $c_{1}(k)=c_{2}(k)$. The equilibrium must therefore be unique. 


\section{B Proof of Lemma 2}

As the asset price $q_{t}$ tends to infinity, the marginal utility of wealth $\gamma^{\prime}\left(k_{t}+q_{t}\right)$ tends to zero. Hence, by (28), the interest rate $f^{\prime}\left(k_{t}\right)-\delta$ tends to $\rho{ }^{27}$ The asset pricing equation (30) implies that, as $q_{t}$ tends to infinity, the price of the asset must eventually grow at rate $f^{\prime}\left(k_{t}\right)-\delta-n$ and, therefore, at rate $\rho-n$. But, this is inconsistent with the transversality condition (31).

\section{Proof of Lemma 3}

The asset pricing equation (30) under the steady state interest rate $r$ can be written as:

$$
\dot{q}_{t}=(r-n) q_{t}-z e^{-\theta t}
$$

Integrating this equation from time 0 to $t$ yields:

$$
\begin{gathered}
\frac{d e^{-(r-n) s} q_{s}}{d s}=-e^{-(r-n) s} z e^{-\theta s}, \\
e^{-(r-n) t} q_{t}-q_{0}=-z \int_{0}^{t} e^{-(r-n+\theta) s} d s, \\
q_{t}=e^{(r-n) t} q_{0}-z e^{-\theta t} \int_{0}^{t} e^{(r-n+\theta)(t-s)} d s .
\end{gathered}
$$

This implies:

$$
\begin{aligned}
q_{t} & =e^{(r-n) t} q_{0}-z e^{-\theta t} \int_{0}^{t} d\left(\frac{-e^{(r-n+\theta)(t-s)}}{r-n+\theta}\right), \\
& =e^{(r-n) t} q_{0}-z e^{-\theta t} \frac{e^{(r-n+\theta) t}-1}{r-n+\theta} \\
& =\frac{z e^{-\theta t}}{r-n+\theta}+e^{(r-n) t}\left[q_{0}-\frac{z}{r-n+\theta}\right] .
\end{aligned}
$$

We can therefore express the asset price as:

$$
q_{t}=e^{-\theta t}\left[\frac{z}{r-n+\theta}+e^{(r-n+\theta) t}\left[q_{0}-\frac{z}{r-n+\theta}\right]\right] .
$$

Thus, if $r-n+\theta<0$, then $q_{t}$ tends to $z e^{-\theta t} /(r-n+\theta)$, which is negative. But, as the asset can be freely disposed of, its price can never be negative. Hence, we cannot have

\footnotetext{
${ }^{27}$ An alternative would be to have $c_{t}$ tending to zero and $\dot{c}_{t} / c_{t}$ tending to a negative constant. However, from (29), this can only be consistent with a steady state equilibrium such that $k=\bar{k}$ where $\bar{k}$ is the solution to $f(\bar{k})+z=(\delta+n) \bar{k}$. However, this steady state implies that $f^{\prime}(k)-\delta-n=f^{\prime}(\bar{k})-\delta-n<0$. By the asset pricing equation (30), this is inconsistent with an ever increasing asset price $q_{t}$.
} 
$r<n-\theta$. Also, if $r=n-\theta$, then, from (C1), we have:

$$
\begin{aligned}
q_{t} & =e^{(r-n) t} q_{0}-z e^{-\theta t} t \\
& =e^{-\theta t}\left[q_{0}-z t\right]
\end{aligned}
$$

which must also eventually be negative. Hence, we also cannot have $r=n-\theta$.

\section{Proof of Lemma 4}

By (C2), if $q_{0}<z /(r-n+\theta)$ with $r>n-\theta$, then $q_{t}$ must eventually be negative. But, as the asset can be freely disposed of, its price can never be negative. Thus, $q_{0} \geq$ $z /(r-n+\theta)$, which implies by $(\mathrm{C} 2)$ that $q_{t} \geq z /(r-n+\theta)$ for all $t$. The asset price cannot be below its fundamental value.

\section{E Proof of Lemma 5}

The steady state equilibrium with $\theta=0$ is jointly characterized by (40), (41), and (42). Equation (42) immediately implies that any steady state equilibrium must be bubble-less. Also, as $q$ must be positive, we must have $f^{\prime}(k)-\delta>n$, i.e. $r>n$. Let $\tilde{k}$ and $k^{*}$ be defined by $f^{\prime}(\tilde{k})-\delta=\rho$ and $f^{\prime}\left(k^{*}\right)-\delta=n$, respectively. Note that, as $\rho \geq n$, we must have $\tilde{k} \leq k^{*}$.

Substituting (42) into (40) yields:

$$
u^{\prime}(c)=\frac{1}{\rho+\delta-f^{\prime}(k)} \gamma^{\prime}\left(k+\frac{z}{f^{\prime}(k)-\delta-n}\right) .
$$

This equation defines $c$ as a continuous and strictly increasing function of $k$ for all $k \in$ $\left(\tilde{k}, k^{*}\right)$. Also, $c$ tends to 0 as $k$ tends to $\tilde{k}$ from above. In addition, as $k$ tends to $k^{*}$ from below, the asset price $q$ tends to infinity and hence $\gamma^{\prime}$ tends to zero. Therefore, $c$ tends to infinity. Let us call the resulting function $c_{1}$.

Let $\hat{k}$ be defined as $f(\hat{k})+z=(\delta+n) \hat{k}$, where we trivially have $\hat{k}>k^{*}$. Equation (41) defines $c$ as a continuous function of $k$, which is increasing on $\left[0, k^{*}\right)$ and decreasing on $\left(k^{*}, \hat{k}\right]$. Also, $c$ is equal to 0 when $k$ is equal to $\hat{k}$. Let us call this function $c_{2}$.

An equilibrium is characterized by an value of $k$ that satisfies $c_{1}(k)=c_{2}(k)$. We have therefore shown that $c_{1}$ is continuous and increasing on $\left(\tilde{k}, k^{*}\right)$ with $\lim _{k \rightarrow \tilde{k}+} c(k)=0$ and $\lim _{k \rightarrow k^{*}-} c(k)=\infty$. Also, $c_{2}$ is positive and continuous on $[0, \hat{k}]$ with $c_{2}(\hat{k})=0$. An equilibrium must therefore exist on $\left(\tilde{k}, k^{*}\right)$.

We know that $q>0$. Assumption 1 immediately implies that the equilibrium capital stock with $q>0$ is smaller than in the corresponding equilibrium with $q=0$. Thus, 
$r>\bar{r}$.

Uniqueness of the equilibrium requires the slope of $c_{1}$ to exceed the slope of $c_{2}$ at each intersection of both lines in the $k-c$ diagram. We have:

$$
\begin{array}{r}
\frac{\partial c_{1}}{\partial k}-\frac{\partial c_{2}}{\partial k}=\frac{\gamma^{\prime \prime}(k+q)}{u^{\prime \prime}(c)\left[\rho+\delta-f^{\prime}(k)\right]}\left[1-\frac{z f^{\prime \prime}(k)}{\left[f^{\prime}(k)-\delta-n\right]^{2}}\right] \\
\quad+\frac{f^{\prime \prime}(k) \gamma^{\prime}(k+q)}{u^{\prime \prime}(c)\left[\rho+\delta-f^{\prime}(k)\right]^{2}}-\left[f^{\prime}(k)-\delta-n\right], \\
=\frac{-\gamma^{\prime \prime}(k+q)}{u^{\prime \prime}(c)} \frac{u^{\prime}(c)}{\gamma^{\prime}(k+q)}\left[-1-\frac{f^{\prime \prime}(k) u^{\prime}(c)}{\gamma^{\prime \prime}(k+q)}\right. \\
\left.+\frac{u^{\prime \prime}(c)}{\gamma^{\prime \prime}(k+q)} \frac{\gamma^{\prime}(k+q)}{u^{\prime}(c)}\left[f^{\prime}(k)-\delta-n\right]\right] \\
-\frac{\gamma^{\prime \prime}(k+q)}{u^{\prime \prime}(c)} \frac{u^{\prime}(c)}{\gamma^{\prime}(k+q)} \frac{z f^{\prime \prime}(k)}{\left[f^{\prime}(k)-\delta-n\right]^{2}} .
\end{array}
$$

Compared to the corresponding expression of Lemma 1, we have a new term (the last term), which is positive. Hence, under Assumption 1 (which guarantees that the term in the main bracket is negative), we still have:

$$
\frac{\partial c_{1}}{\partial k}-\frac{\partial c_{2}}{\partial k}>0
$$

for all $k$ such that $c_{1}(k)=c_{2}(k)$. The equilibrium must therefore be unique.

\section{F Proof of Lemma 6}

For any $\theta>0$, the fundamental value of the asset converges to zero. Hence, a steady state with $q>0$ must be bubbly.

If a bubbly steady state equilibrium exists, it must be characterized by (40), (41), and (43). Equation (43) uniquely determines $k$; then equation (41) uniquely determines $c$; and then finally equation (40) uniquely determines $q$.

To prove that such an equilibrium exists, it is sufficient to show that $q>0$ (since, from Lemma 3 and 4 , there cannot be a steady state with $q<0$ and, if $q=0$, then there is no bubble). Let $\tilde{k}$ and $\bar{k}$ be defined as $f^{\prime}(\tilde{k})-\delta=\rho$ and $f^{\prime}(\bar{k})-\delta=\bar{r}$ (thus, $\bar{k}$ is the capital stock under Lemma 1, i.e. without the infinitely-lived asset). As $\bar{r}<\rho$, we must have $\tilde{k}<\bar{k}$. Combining (40) and (41) yields $\gamma^{\prime}(k+q)=\left[\rho+\delta-f^{\prime}(k)\right] u^{\prime}(f(k)+z-(\delta+n) k)$. This defines $q$ a positive and continuous function of $k$ with $q(\bar{k})=0$ and $\lim _{k \rightarrow \tilde{k}+} q(k)=+\infty$. $^{28}$

\footnotetext{
${ }^{28}$ If there is a unique value of $\bar{r}$ (i.e. there is a unique solution to $\gamma^{\prime}(k)=\left[\rho+\delta-f^{\prime}(k)\right] u^{\prime}(f(k)+z-$ $(\delta+n) k)$ ), then there is no $k \in(\bar{k}, \bar{k})$ such that $q(k)=0$. Thus, $q(k)>0$ for all $k \in(\tilde{k}, \bar{k})$. If there are multiple values of $\bar{r}$, then the argument applies when taking the largest value of $\bar{r}$, i.e. the smallest value of $\bar{k}$.
} 
We always $\rho>n$. If in addition $n>\bar{r}$, then the equilibrium value of $k$ given by (43) satisfies $k \in(\tilde{k}, \bar{k})$. The corresponding value of $q$ determined by (40) and (41) is given by $q(k)$ and it satisfies $q(k)>0$. This proves the existence of a unique bubbly steady state equilibrium whenever $\bar{r}<n$.

Let us now consider the case where $\bar{r} \geq n$. Under Assumption 1, $q$ is a strictly decreasing function of $k$. But, $q(\bar{k})=0$. Hence, the existence of an equilibrium with $q>0$ requires $k<\bar{k}$ or, equivalently, $r>\bar{r}$. But, if $\bar{r} \geq n$, then this requires $r>n$, which is inconsistent with the asset pricing equation (43). Thus, under Assumption 1, there cannot exist a bubbly steady state equilibrium whenever $\bar{r} \geq n$.

\section{G $\quad$ Proof of Lemma 7}

If a bubble-less steady state equilibrium exists, it must be characterized by (40), (41), and (44). By Lemma 1, such an equilibrium always exist and, under Assumption 1, it must be unique. This equilibrium must trivially satisfy $r=\bar{r}$.

Finally, by Lemma 3 , if $\bar{r} \leq n-\theta$, then for any finite value of time $t$ there cannot be an equilibrium with $r=\bar{r}$. In that case the (asymptotic) steady state is not economically meaningful (since it can only exist in the limit as $t$ tends to infinity).

\section{H Proof of Lemma 8}

From (40), (41), and (43), the bubbly steady state $\left(c^{B}, k^{B}, q^{B}\right)$ is characterized by:

$$
\begin{gathered}
f^{\prime}\left(k^{B}\right)-\delta=n, \\
c^{B}=f\left(k^{B}\right)+z-(\delta+n) k^{B}, \\
n=\rho-\frac{\gamma^{\prime}\left(k^{B}+q^{B}\right)}{u^{\prime}\left(c^{B}\right)} .
\end{gathered}
$$

From (40), (41), and (44), the non-bubbly steady state $(\bar{c}, \bar{k}, 0)$ is characterized by:

$$
\begin{gathered}
f^{\prime}(\bar{k})-\delta=\rho-\frac{\gamma^{\prime}(\bar{k})}{u^{\prime}(\bar{c})}, \\
\bar{c}=f(\bar{k})+z-(\delta+n) \bar{k} .
\end{gathered}
$$

As $k^{B}$ is the golden rule capital stock, when $\bar{r}<n$, we clearly have $\bar{c}<c^{B}$ and $\bar{k}>k^{B}$. From the above equations, we have:

$$
\gamma^{\prime}\left(k^{B}+q^{B}\right)=(\rho-n) u^{\prime}\left(c^{B}\right)<(\rho-n) u^{\prime}(\bar{c})=\frac{\rho-n}{\rho-\left[f^{\prime}(\bar{k})-\delta\right]} \gamma^{\prime}(\bar{k})
$$


As $\rho-\left[f^{\prime}(\bar{k})-\delta\right]>\rho-n>0$, we have:

$$
\frac{\rho-n}{\rho-\left[f^{\prime}(\bar{k})-\delta\right]}<1
$$

Hence:

$$
\gamma^{\prime}\left(k^{B}+q^{B}\right)<\gamma^{\prime}(\bar{k}) .
$$

This establishes that $k^{B}+q^{B}>\bar{k}$. It immediately follows that:

$$
u\left(c^{B}\right)+\gamma\left(k^{B}+q^{B}\right)>u(\bar{c})+\gamma(\bar{k})
$$

\section{Proof of Lemma 9}

Linearizing the system (28), (29), and (30) around a steady state $\left(k^{*}, c^{*}, q^{*}\right)$ yields:

$$
\left(\begin{array}{c}
\dot{k}_{t} \\
\dot{c}_{t} \\
\dot{q}_{t}
\end{array}\right)=\left(\begin{array}{ccc}
f^{\prime}\left(k^{*}\right)-\delta-n & -1 & 0 \\
{\left[f^{\prime \prime}\left(k^{*}\right)+\frac{\gamma^{\prime \prime}\left(k^{*}+q^{*}\right)}{u^{\prime}\left(c^{*}\right)}\right] \frac{c^{*}}{\varepsilon\left(c^{*}\right)}} & \frac{\gamma^{\prime}\left(k^{*}+q^{*}\right)}{u^{\prime}\left(c^{*}\right)} & \frac{\gamma^{\prime \prime}\left(k^{*}+q^{*}\right)}{u^{\prime}\left(c^{*}\right)} \frac{c^{*}}{\varepsilon\left(c^{*}\right)} \\
f^{\prime \prime}\left(k^{*}\right) q^{*} & 0 & f^{\prime}\left(k^{*}\right)-\delta-n
\end{array}\right)\left(\begin{array}{c}
k_{t}-k^{*} \\
c_{t}-c^{*} \\
q_{t}-q^{*}
\end{array}\right)
$$

where $\varepsilon(c)=-c u^{\prime \prime}(c) / u^{\prime}(c)$. The steady state is characterized by (42), which implies that $f^{\prime}\left(k^{*}\right)-\delta-n=z / q^{*}$. Hence:

$$
\left(\begin{array}{c}
\dot{k}_{t} \\
\dot{c}_{t} \\
\dot{q}_{t}
\end{array}\right)=\left(\begin{array}{ccc}
\frac{z}{q^{*}} & -1 & 0 \\
{\left[f^{\prime \prime}\left(k^{*}\right)+\frac{\gamma^{\prime \prime}\left(k^{*}+q^{*}\right)}{u^{\prime}\left(c^{*}\right)}\right] \frac{c^{*}}{\varepsilon\left(c^{*}\right)}} & \frac{\gamma^{\prime}\left(k^{*}+q^{*}\right)}{u^{\prime}\left(c^{*}\right)} & \frac{\gamma^{\prime \prime}\left(k^{*}+q^{*}\right)}{u^{\prime}\left(c^{*}\right)} \frac{c^{*}}{\varepsilon\left(c^{*}\right)} \\
f^{\prime \prime}\left(k^{*}\right) q^{*} & 0 & \frac{z}{q^{*}}
\end{array}\right)\left(\begin{array}{c}
k_{t}-k^{*} \\
c_{t}-c^{*} \\
q_{t}-q^{*}
\end{array}\right) .
$$

The eigenvalues $\alpha_{1}, \alpha_{2}$, and $\alpha_{3}$ of the matrix are the solution to:

$$
\begin{aligned}
\left(\frac{z}{q^{*}}-x\right)^{2}\left(\frac{\gamma^{\prime}\left(k^{*}+q^{*}\right)}{u^{\prime}\left(c^{*}\right)}-x\right)+\left(\frac{z}{q^{*}}-x\right)\left[f^{\prime \prime}\left(k^{*}\right)+\frac{\gamma^{\prime \prime}\left(k^{*}+q^{*}\right)}{u^{\prime}\left(c^{*}\right)}\right] & \frac{c^{*}}{\varepsilon\left(c^{*}\right)} \\
& -\frac{\gamma^{\prime \prime}\left(k^{*}+q^{*}\right)}{u^{\prime}\left(c^{*}\right)} \frac{c^{*}}{\varepsilon\left(c^{*}\right)} f^{\prime \prime}\left(k^{*}\right) q^{*}=0 .
\end{aligned}
$$

The characteristic equation of the matrix can be written as:

$$
\begin{gathered}
-\left(x-\alpha_{1}\right)\left(x-\alpha_{2}\right)\left(x-\alpha_{3}\right)=0 \\
-x^{3}+\left(\alpha_{1}+\alpha_{2}+\alpha_{3}\right) x^{2}-\left(\alpha_{1} \alpha_{2}+\alpha_{1} \alpha_{3}+\alpha_{2} \alpha_{3}\right) x+\alpha_{1} \alpha_{2} \alpha_{3}=0,
\end{gathered}
$$

where:

$$
\alpha_{1}+\alpha_{2}+\alpha_{3}=\frac{\gamma^{\prime}\left(k^{*}+q^{*}\right)}{u^{\prime}\left(c^{*}\right)}+2 \frac{z}{q^{*}}>0 .
$$


We also have:

$$
\alpha_{1} \alpha_{2} \alpha_{3}=\frac{z}{q^{*}}\left[\frac{z}{q^{*}} \frac{\gamma^{\prime}\left(k^{*}+q^{*}\right)}{u^{\prime}\left(c^{*}\right)}+\left[f^{\prime \prime}\left(k^{*}\right)+\frac{\gamma^{\prime \prime}\left(k^{*}+q^{*}\right)}{u^{\prime}\left(c^{*}\right)}\left(1-f^{\prime \prime}\left(k^{*}\right) \frac{\left(q^{*}\right)^{2}}{z}\right)\right] \frac{c^{*}}{\varepsilon\left(c^{*}\right)}\right] .
$$

Assuming that the steady state equilibrium is unique, we know (from the proof of Lemma 5) that in the neighborhood of the steady state:

$$
\left.\frac{\partial c_{t}}{\partial k_{t}}\right|_{\dot{c}_{t}=0}>\left.\frac{\partial c_{t}}{\partial k_{t}}\right|_{\dot{k}_{t}=0}
$$

Indeed, for a given value of $q_{t}$, the $\dot{c}_{t}=0$ locus is steeper than the $\dot{k}_{t}=0$ locus. The $\dot{c}_{t}=0$ locus is given by (40). Implicitly differentiating this equation at the steady state yields:

$$
f^{\prime \prime}\left(k^{*}\right)=\frac{-\gamma^{\prime \prime}\left(k^{*}+q^{*}\right)}{u^{\prime}\left(c^{*}\right)}+\left.\frac{\gamma^{\prime}\left(k^{*}+q^{*}\right)}{\left[u^{\prime}\left(c^{*}\right)\right]^{2}} u^{\prime \prime}\left(c^{*}\right) \frac{\partial c_{t}}{\partial k_{t}}\right|_{\dot{c}_{t}=0} .
$$

Thus:

$$
\begin{aligned}
\left.\frac{\partial c_{t}}{\partial k_{t}}\right|_{\dot{c}_{t}=0} & =\frac{u^{\prime}\left(c^{*}\right)}{\gamma^{\prime}\left(k^{*}+q^{*}\right)}\left[f^{\prime \prime}\left(k^{*}\right)+\frac{\gamma^{\prime \prime}\left(k^{*}+q^{*}\right)}{u^{\prime}\left(c^{*}\right)}\right] \frac{u^{\prime}\left(c^{*}\right)}{u^{\prime \prime}\left(c^{*}\right)}, \\
& =\frac{u^{\prime}\left(c^{*}\right)}{\gamma^{\prime}\left(k^{*}+q^{*}\right)}\left[f^{\prime \prime}\left(k^{*}\right)+\frac{\gamma^{\prime \prime}\left(k^{*}+q^{*}\right)}{u^{\prime}\left(c^{*}\right)}\right] \frac{-c^{*}}{\varepsilon\left(c^{*}\right)} .
\end{aligned}
$$

Similarly, the $\dot{k}_{t}=0$ locus is given by (41). Implicitly differentiating it at the steady state yields:

$$
\left.\frac{\partial c_{t}}{\partial k_{t}}\right|_{\dot{k}_{t}=0}=f^{\prime}\left(k^{*}\right)-\delta-n=\frac{z}{q^{*}}
$$

Combining these results implies that:

$$
\frac{u^{\prime}\left(c^{*}\right)}{\gamma^{\prime}\left(k^{*}+q^{*}\right)}\left[f^{\prime \prime}\left(k^{*}\right)+\frac{\gamma^{\prime \prime}\left(k^{*}+q^{*}\right)}{u^{\prime}\left(c^{*}\right)}\right] \frac{-c^{*}}{\varepsilon\left(c^{*}\right)}>\frac{z}{q^{*}},
$$

or equivalently:

$$
\left[f^{\prime \prime}\left(k^{*}\right)+\frac{\gamma^{\prime \prime}\left(k^{*}+q^{*}\right)}{u^{\prime}\left(c^{*}\right)}\right] \frac{c^{*}}{\varepsilon\left(c^{*}\right)}+\frac{\gamma^{\prime}\left(k^{*}+q^{*}\right)}{u^{\prime}\left(c^{*}\right)} \frac{z}{q^{*}}<0 .
$$

This implies that:

$$
\alpha_{1} \alpha_{2} \alpha_{3}<0
$$

Thus, the left-hand side of the characteristic equation is equal to $\alpha_{1} \alpha_{2} \alpha_{3}<0$ if $x$ is equal to zero and it tends to infinity if $x$ tends to minus infinity. Hence, there exists at least one real value of $x$ smaller than zero such that the left-hand side is equal to zero, i.e. the matrix has at least one negative real eigenvalue. Let $\alpha_{1}$ be this negative eigenvalue. 
As $\alpha_{1}<0$, we must have $\alpha_{2}+\alpha_{3}>0$ and $\alpha_{2} \alpha_{3}>0$. Hence, if $\alpha_{2}$ and $\alpha_{3}$ are real, then we must have $\alpha_{2}>0$ and $\alpha_{3}>0$. If $\alpha_{2}$ and $\alpha_{3}$ are complex, then, as their sum is real, they must be complex conjugate of one another. Moreover, as $\alpha_{2}+\alpha_{3}>0$, their real part must be positive.

Finally, we need to show that there cannot be a bubble along a trajectory converging to the steady state. Recall that the bubble component must grow at rate $f^{\prime}\left(k_{t}\right)-\delta-n$, which is positive in the neighborhood of the steady state. Thus, a bubble would be growing as it approaches the steady state. But, the steady state is bubble-less. Thus, a trajectory converging to the steady state must also be bubble-less.

\section{J Proof of Lemma 10}

The system of differential equations linearized around a steady state $\left(k^{*}, c^{*}, q^{*}\right)$ can be written as:

$$
\dot{u}_{t}=A u_{t}+v_{t}
$$

where $u_{t}=\left(k_{t}-k^{*}, c_{t}-c^{*}, q_{t}-q^{*}\right)^{T}$ and $v_{t}=\left(0,0, z e^{-\theta t}\right)^{T}$. Let $D$ be a diagonal matrix of eigenvalues and $P$ a matrix of eigenvectors of $A$, i.e. $A P=P D$. Let $x_{t}$ be defined as $x_{t}=P^{-1} u_{t}$. We therefore have:

$$
\dot{x}_{t}=P^{-1} \dot{u}_{t}=P^{-1} A u_{t}+P^{-1} v_{t}=P^{-1} A P x_{t}+P^{-1} v_{t}=D x_{t}+P^{-1} v_{t} .
$$

Since $D$ is a diagonal matrix, we obtain three independent linear differential equations. Each of these differential equations is of the following form:

$$
\dot{x}_{1}(t)=\alpha_{1} x_{1}(t)+\beta_{1} e^{-\theta t},
$$

where $x_{1}(t)$ is the first element of the vector $x_{t}, \alpha_{1}$ is an eigenvalue, and $\beta_{1}$ is a constant. Integrating this linear differential equation yields:

$$
\begin{gathered}
\frac{d e^{-\alpha_{1} t} x_{1}(t)}{d t}=\beta_{1} e^{-\left(\alpha_{1}+\theta\right) t}, \\
e^{-\alpha_{1} t} x_{1}(t)-x_{1}(0)=\beta_{1} \int_{0}^{t} e^{-\left(\alpha_{1}+\theta\right) s} d s \\
x_{1}(t)=e^{\alpha_{1} t}\left[x_{1}(0)+\beta_{1} \int_{0}^{t} e^{-\left(\alpha_{1}+\theta\right) s} d s\right] .
\end{gathered}
$$


If $\alpha_{1}+\theta \neq 0$, which should generically be the $\operatorname{case}^{29}$, then:

$$
\begin{aligned}
x_{1}(t) & =e^{\alpha_{1} t}\left[x_{1}(0)+\beta_{1}\left[\frac{1-e^{-\left(\alpha_{1}+\theta\right) t}}{\alpha_{1}+\theta}\right]\right], \\
& =e^{\alpha_{1} t}\left[x_{1}(0)+\frac{\beta_{1}}{\alpha_{1}+\theta}\right]-e^{-\theta t} \frac{\beta_{1}}{\alpha_{1}+\theta} .
\end{aligned}
$$

Thus, the second term tends to zero, while the first term has the same structure as for the solution to a homogeneous and autonomous system of linear differential equations, i.e. it consists of a constant determined by initial conditions multiplied by $e^{\alpha_{1} t}$. Hence, the local stability of our system of differential equations $\dot{u}_{t}=A u_{t}+v_{t}$ is determined by the eigenvalues of the matrix $A$, as if the system was homogenous and autonomous. ${ }^{30}$

\section{K Proof of Lemma 11}

Linearizing the system (28), (29), and (30) around a steady state $\left(k^{*}, c^{*}, q^{*}\right)$ yields:

$$
\left(\begin{array}{c}
\dot{k}_{t} \\
\dot{c}_{t} \\
\dot{q}_{t}
\end{array}\right)=\left(\begin{array}{ccc}
f^{\prime}\left(k^{*}\right)-\delta-n & -1 & 0 \\
{\left[f^{\prime \prime}\left(k^{*}\right)+\frac{\gamma^{\prime \prime}\left(k^{*}+q^{*}\right)}{u^{\prime}\left(c^{*}\right)}\right] \frac{c^{*}}{\varepsilon\left(c^{*}\right)}} & \frac{\gamma^{\prime}\left(k^{*}+q^{*}\right)}{u^{\prime}\left(c^{*}\right)} & \frac{-\gamma^{\prime \prime}\left(k^{*}+q^{*}\right)}{u^{\prime \prime}\left(c^{*}\right)} \\
f^{\prime \prime}\left(k^{*}\right) q^{*} & 0 & f^{\prime}\left(k^{*}\right)-\delta-n
\end{array}\right)\left(\begin{array}{c}
k_{t}-k^{*} \\
c_{t}-c^{*} \\
q_{t}-q^{*}
\end{array}\right)+\left(\begin{array}{c}
0 \\
0 \\
z e^{-\theta t}
\end{array}\right),
$$

where $\varepsilon(c)=-c u^{\prime \prime}(c) / u^{\prime}(c)$. The bubbly steady state is characterized by (43), i.e. $f^{\prime}\left(k^{*}\right)=\delta+n$. Also, by (40), we have $\gamma^{\prime}\left(k^{*}+q^{*}\right) / u^{\prime}\left(c^{*}\right)=\rho-\left[f^{\prime}\left(k^{*}\right)-\delta\right]=\rho-n$.

The linearized system can therefore be simplified to:

$$
\left(\begin{array}{c}
\dot{k}_{t} \\
\dot{c}_{t} \\
\dot{q}_{t}
\end{array}\right)=\left(\begin{array}{ccc}
0 & -1 & 0 \\
{\left[f^{\prime \prime}\left(k^{*}\right)+\frac{\gamma^{\prime \prime}\left(k^{*}+q^{*}\right)}{u^{\prime}\left(c^{*}\right)}\right] \frac{c^{*}}{\varepsilon\left(c^{*}\right)}} & \rho-n & \frac{-\gamma^{\prime \prime}\left(k^{*}+q^{*}\right)}{u^{\prime \prime}\left(c^{*}\right)} \\
f^{\prime \prime}\left(k^{*}\right) q^{*} & 0 & 0
\end{array}\right)\left(\begin{array}{c}
k_{t}-k^{*} \\
c_{t}-c^{*} \\
q_{t}-q^{*}
\end{array}\right)+\left(\begin{array}{c}
0 \\
0 \\
z e^{-\theta t}
\end{array}\right) .
$$

The eigenvalues $\alpha_{1}, \alpha_{2}$, and $\alpha_{3}$ of the matrix are the solution to:

$$
x^{2}(\rho-n-x)-x\left[f^{\prime \prime}\left(k^{*}\right)+\frac{\gamma^{\prime \prime}\left(k^{*}+q^{*}\right)}{u^{\prime}\left(c^{*}\right)}\right] \frac{c^{*}}{\varepsilon\left(c^{*}\right)}+\frac{\gamma^{\prime \prime}\left(k^{*}+q^{*}\right)}{u^{\prime \prime}\left(c^{*}\right)} f^{\prime \prime}\left(k^{*}\right) q^{*}=0 .
$$

The left-hand side of this expression is a continuous function of $x$, which is negative when $x=0$ and tends to infinity as $x$ tends to minus infinity. Hence, there exists at least one real value of $x$ smaller than zero such that the left-hand side is equal to zero, i.e. the matrix has at least one negative real eigenvalue. Let $\alpha_{1}$ be this negative eigenvalue.

\footnotetext{
${ }^{29}$ Note that $\theta$ does not enter the matrix $A$ from which the eigenvalue $\alpha_{1}$ is derived.

${ }^{30}$ Recall that, for a given set of initial conditions $k_{0}, c_{0}$, and $q_{0}$, a trajectory is said to be stable if $u_{t}$, and therefore $x_{t}$, tend to zero as time tends to infinity.
} 
The characteristic equation of the matrix can be written as:

$$
\begin{gathered}
-\left(x-\alpha_{1}\right)\left(x-\alpha_{2}\right)\left(x-\alpha_{3}\right)=0, \\
-x^{3}+\left(\alpha_{1}+\alpha_{2}+\alpha_{3}\right) x^{2}-\left(\alpha_{1} \alpha_{2}+\alpha_{1} \alpha_{3}+\alpha_{2} \alpha_{3}\right) x+\alpha_{1} \alpha_{2} \alpha_{3}=0,
\end{gathered}
$$

where:

$$
\begin{gathered}
\alpha_{1}+\alpha_{2}+\alpha_{3}=\rho-n>0, \\
\alpha_{1} \alpha_{2} \alpha_{3}=\frac{\gamma^{\prime \prime}\left(k^{*}+q^{*}\right)}{u^{\prime \prime}\left(c^{*}\right)} f^{\prime \prime}\left(k^{*}\right) q^{*}<0 .
\end{gathered}
$$

As $\alpha_{1}<0$, we must have $\alpha_{2}+\alpha_{3}>0$ and $\alpha_{2} \alpha_{3}>0$. Hence, if $\alpha_{2}$ and $\alpha_{3}$ are real, then we must have $\alpha_{2}>0$ and $\alpha_{3}>0$. If $\alpha_{2}$ and $\alpha_{3}$ are complex, then, as their sum is real, they must be complex conjugate of one another. Moreover, as $\alpha_{2}+\alpha_{3}>0$, their real part must be positive.

\section{Proof of Lemma 12}

The bubble-less steady state is characterized by (44), i.e. $q^{*}=0$. Hence, the linearized system of differential equations around this steady state is:

$$
\left(\begin{array}{c}
\dot{k}_{t} \\
\dot{c}_{t} \\
\dot{q}_{t}
\end{array}\right)=\left(\begin{array}{ccc}
f^{\prime}\left(k^{*}\right)-\delta-n & -1 & 0 \\
{\left[f^{\prime \prime}\left(k^{*}\right)+\frac{\gamma^{\prime \prime}\left(k^{*}\right)}{u^{\prime}\left(c^{*}\right)}\right] \frac{c^{*}}{\varepsilon\left(c^{*}\right)}} & \frac{\gamma^{\prime}\left(k^{*}\right)}{u^{\prime}\left(c^{*}\right)} & \frac{-\gamma^{\prime \prime}\left(k^{*}\right)}{u^{\prime \prime}\left(c^{*}\right)} \\
0 & 0 & f^{\prime}\left(k^{*}\right)-\delta-n
\end{array}\right)\left(\begin{array}{c}
k_{t}-k^{*} \\
c_{t}-c^{*} \\
q_{t}-q^{*}
\end{array}\right)+\left(\begin{array}{c}
0 \\
0 \\
z e^{-\theta t}
\end{array}\right) .
$$

The eigenvalues $\alpha_{1}, \alpha_{2}$, and $\alpha_{3}$ of the matrix are the solution to:

$$
\left[f^{\prime}\left(k^{*}\right)-\delta-n-x\right]^{2}\left[\frac{\gamma^{\prime}\left(k^{*}\right)}{u^{\prime}\left(c^{*}\right)}-x\right]+\left[f^{\prime}\left(k^{*}\right)-\delta-n-x\right]\left[f^{\prime \prime}\left(k^{*}\right)+\frac{\gamma^{\prime \prime}\left(k^{*}\right)}{u^{\prime}\left(c^{*}\right)}\right] \frac{c^{*}}{\varepsilon\left(c^{*}\right)}=0 .
$$

This can be simplified to:

$$
\begin{aligned}
{\left[f^{\prime}\left(k^{*}\right)-\delta-n-x\right]\left(\left[f^{\prime}\left(k^{*}\right)-\delta-n-x\right]\left[\frac{\gamma^{\prime}\left(k^{*}\right)}{u^{\prime}\left(c^{*}\right)}-x\right]\right.} \\
\left.+\left[f^{\prime \prime}\left(k^{*}\right)+\frac{\gamma^{\prime \prime}\left(k^{*}\right)}{u^{\prime}\left(c^{*}\right)}\right] \frac{c^{*}}{\varepsilon\left(c^{*}\right)}\right)=0,
\end{aligned}
$$




$$
\begin{array}{r}
{\left[f^{\prime}\left(k^{*}\right)-\delta-n-x\right]\left(x^{2}-\left[f^{\prime}\left(k^{*}\right)-\delta-n+\frac{\gamma^{\prime}\left(k^{*}\right)}{u^{\prime}\left(c^{*}\right)}\right] x+\left[f^{\prime}\left(k^{*}\right)-\delta-n\right] \frac{\gamma^{\prime}\left(k^{*}\right)}{u^{\prime}\left(c^{*}\right)}\right.} \\
\left.+\left[f^{\prime \prime}\left(k^{*}\right)+\frac{\gamma^{\prime \prime}\left(k^{*}\right)}{u^{\prime}\left(c^{*}\right)}\right] \frac{c^{*}}{\varepsilon\left(c^{*}\right)}\right)=0 .
\end{array}
$$

But, by $(40), f^{\prime}\left(k^{*}\right)-\delta+\gamma^{\prime}\left(k^{*}\right) / u^{\prime}\left(c^{*}\right)=\rho$. Thus:

$$
\begin{aligned}
{\left[f^{\prime}\left(k^{*}\right)-\delta-n-x\right]\left(x^{2}-(\rho-n) x+\left[f^{\prime}\left(k^{*}\right)-\delta\right.\right.} & -n] \frac{\gamma^{\prime}\left(k^{*}\right)}{u^{\prime}\left(c^{*}\right)} \\
& \left.+\left[f^{\prime \prime}\left(k^{*}\right)+\frac{\gamma^{\prime \prime}\left(k^{*}\right)}{u^{\prime}\left(c^{*}\right)}\right] \frac{c^{*}}{\varepsilon\left(c^{*}\right)}\right)=0 .
\end{aligned}
$$

One eigenvalue is equal to $f^{\prime}\left(k^{*}\right)-\delta-n=\bar{r}-n$. Thus, let $\alpha_{1}=\bar{r}-n$. The other two eigenvalues $\alpha_{2}$ and $\alpha_{3}$ are the solutions to the quadratic equation $x^{2}-(\rho-n) x+\chi=0$, where we need to determine the sign of the constant $\chi$.

Assuming that the steady state equilibrium is unique, we know (from the proof of Lemma 1) that in the neighborhood of the steady state:

$$
\left.\frac{\partial c_{t}}{\partial k_{t}}\right|_{\dot{c}_{t}=0}>\left.\frac{\partial c_{t}}{\partial k_{t}}\right|_{\dot{k}_{t}=0}
$$

Indeed, for $q_{t}=0$, the $\dot{c}_{t}=0$ locus is steeper than the $\dot{k}_{t}=0$ locus. The $\dot{c}_{t}=0$ locus is given by (40). Implicitly differentiating this equation at the steady state yields:

$$
f^{\prime \prime}\left(k^{*}\right)=\frac{-\gamma^{\prime \prime}\left(k^{*}\right)}{u^{\prime}\left(c^{*}\right)}+\left.\frac{\gamma^{\prime}\left(k^{*}\right)}{\left[u^{\prime}\left(c^{*}\right)\right]^{2}} u^{\prime \prime}\left(c^{*}\right) \frac{\partial c_{t}}{\partial k_{t}}\right|_{\dot{c}_{t}=0} .
$$

Thus:

$$
\begin{aligned}
\left.\frac{\partial c_{t}}{\partial k_{t}}\right|_{\dot{c}_{t}=0} & =\frac{u^{\prime}\left(c^{*}\right)}{\gamma^{\prime}\left(k^{*}\right)}\left[f^{\prime \prime}\left(k^{*}\right)+\frac{\gamma^{\prime \prime}\left(k^{*}\right)}{u^{\prime}\left(c^{*}\right)}\right] \frac{u^{\prime}\left(c^{*}\right)}{u^{\prime \prime}\left(c^{*}\right)} \\
& =\frac{u^{\prime}\left(c^{*}\right)}{\gamma^{\prime}\left(k^{*}\right)}\left[f^{\prime \prime}\left(k^{*}\right)+\frac{\gamma^{\prime \prime}\left(k^{*}\right)}{u^{\prime}\left(c^{*}\right)}\right] \frac{-c^{*}}{\varepsilon\left(c^{*}\right)}
\end{aligned}
$$

Similarly, the $\dot{k}_{t}=0$ locus is given by (41). Implicitly differentiating it at the steady state yields:

$$
\left.\frac{\partial c_{t}}{\partial k_{t}}\right|_{\dot{k}_{t}=0}=f^{\prime}\left(k^{*}\right)-\delta-n .
$$

Combining these results implies that:

$$
\frac{u^{\prime}\left(c^{*}\right)}{\gamma^{\prime}\left(k^{*}\right)}\left[f^{\prime \prime}\left(k^{*}\right)+\frac{\gamma^{\prime \prime}\left(k^{*}\right)}{u^{\prime}\left(c^{*}\right)}\right] \frac{-c^{*}}{\varepsilon\left(c^{*}\right)}>f^{\prime}\left(k^{*}\right)-\delta-n,
$$


or equivalently:

$$
\left[f^{\prime \prime}\left(k^{*}\right)+\frac{\gamma^{\prime \prime}\left(k^{*}\right)}{u^{\prime}\left(c^{*}\right)}\right] \frac{c^{*}}{\varepsilon\left(c^{*}\right)}+\left[f^{\prime}\left(k^{*}\right)-\delta-n\right] \frac{\gamma^{\prime}\left(k^{*}+q^{*}\right)}{u^{\prime}\left(c^{*}\right)}<0 .
$$

This implies that $\alpha_{2}$ and $\alpha_{3}$ are the solutions to the quadratic equation $x^{2}-(\rho-n) x+\chi=$ 0 with $\rho-n>0$ and $\chi<0$. Hence, these two eigenvalues are real, with $\alpha_{2}$ negative and $\alpha_{3}$ positive.

If $\bar{r}>n$, two eigenvalues are positive and one is negative. Hence, for a given value of $k_{0}$, there must be a unique trajectory converging to the steady state.

If $\bar{r}<n$, one eigenvalues is positive and two are negative. In that case, for a given value of $k_{0}$ there is a continuum of values $q_{0}$ that are consistent with convergence to the steady state. ${ }^{31}$ For each pair $k_{0}$ and $q_{0}$ there is at most one value of $c_{0}$ that is consistent with convergence to the steady state.

Finally, we need to show that, when $\bar{r}>n$, there cannot be a bubble along a trajectory converging to the steady state. Recall that the bubble component must grow at rate $f^{\prime}\left(k_{t}\right)-\delta-n$, which is equal to $\bar{r}-n$ at the steady state. Thus, a bubble must be growing in the neighborhood of the steady state. But, the steady state is bubble-less. Thus, when $\bar{r}>n$, a trajectory converging to the steady state must be entirely bubbleless.

\section{Proof of Lemma 13}

To prove the lemma, we need to show that replacing the fiscal policy $\left(\tau_{t}, b_{t}\right)_{t=0}^{\infty}$ by the policy $\left(0, \tilde{b}_{t}\right)_{t=0}^{\infty}$ with $\tilde{b}_{t}=b_{t}-\varphi_{t}$ would leave the allocation $\left(c_{t}, k_{t}\right)_{t=0}^{\infty}$ unchanged.

The equilibrium is characterized by (51), (52), (53), (54), and (55). In the Euler equation (51), we can immediately replace $b_{t}-\varphi_{t}$ by $\tilde{b}_{t}$. The capital accumulation equation (52) is independent of fiscal policy.

By definition of $\varphi_{t}$, given by (46), we have:

$$
\dot{\varphi}_{t}=\left(r_{t}-n\right) \varphi_{t}-\tau_{t} .
$$

\footnotetext{
${ }^{31}$ With two negative eigenvalues, an alternative would be that, for a given value of $k_{0}$, there is a unique value of $q_{0}$ consistent with convergence to the steady state and, for this value of $q_{0}$, there is a continuum of values of $c_{0}$ consistent with convergence to the steady state. However, if this was the case, the transition matrix (from which the eigenvalues are derived) would have a special structure, which is not the case.
} 
The debt accumulation equation (53) can therefore be written as:

$$
\begin{aligned}
\dot{\tilde{b}}_{t} & =\dot{b}_{t}-\dot{\varphi}_{t}, \\
& =\left[\left(r_{t}-n\right) b_{t}-\tau_{t}\right]-\left[\left(r_{t}-n\right) \varphi_{t}-\tau_{t}\right], \\
& =\left(r_{t}-n\right) \tilde{b}_{t},
\end{aligned}
$$

where $r_{t}=f^{\prime}\left(k_{t}\right)-\delta$.

Integrating the above differential equation for $\varphi_{t}$ from time $t$ to infinity yields:

$$
\left(\lim _{T \rightarrow \infty} e^{-\int_{t}^{T}\left(r_{u}-n\right) d u} \varphi_{T}\right)-\varphi_{t}=-\int_{t}^{\infty} e^{-\int_{t}^{s}\left(r_{u}-n\right) d u} \tau_{s} d s .
$$

Thus, if $\varphi_{t}$ is finite, then by definition of $\varphi_{t}$ in (46) we must have:

$$
\lim _{T \rightarrow \infty} e^{-\int_{t}^{T}\left(r_{u}-n\right) d u} \varphi_{T}=0
$$

Also, the consumption Euler equation (51) can be written as:

$$
\frac{d \ln \left[u^{\prime}\left(c_{t}\right)\right]}{d t}=-r_{t}+\rho-\frac{\gamma^{\prime}\left(k_{t}+b_{t}-\varphi_{t}\right)}{u^{\prime}\left(c_{t}\right)} .
$$

Integrating this differential equation from time zero to $t$ yields:

$$
u^{\prime}\left(c_{t}\right)=u^{\prime}\left(c_{0}\right) e^{\int_{0}^{t}\left(\rho-r_{u}-\frac{\gamma^{\prime}\left(k_{u}+\tilde{b}_{u}\right)}{u^{\prime}\left(c_{u}\right)}\right) d u} .
$$

Hence:

$$
\lim _{t \rightarrow \infty} e^{-\int_{0}^{t}\left(\rho-r_{u}\right) d u} u^{\prime}\left(c_{t}\right)=u^{\prime}\left(c_{0}\right) \lim _{t \rightarrow \infty} e^{-\int_{0}^{t} \frac{\gamma^{\prime}\left(k_{u}+\tilde{b}_{u}\right)}{u^{\prime}\left(c_{u}\right)} d u} \leq u^{\prime}\left(c_{0}\right) .
$$

The transversality condition (54) is:

$$
\lim _{t \rightarrow \infty} e^{-(\rho-n) t} u^{\prime}\left(c_{t}\right)\left[k_{t}+\tilde{b}_{t}+\varphi_{t}\right]=0 .
$$

But:

$$
\begin{aligned}
\lim _{t \rightarrow \infty} e^{-(\rho-n) t} u^{\prime}\left(c_{t}\right) \varphi_{t} & =\left(\lim _{t \rightarrow \infty} e^{-\int_{0}^{t}\left(r_{u}-n\right) d u} \varphi_{t}\right)\left(\lim _{t \rightarrow \infty} e^{-\int_{0}^{t}\left(\rho-r_{u}\right) d u} u^{\prime}\left(c_{t}\right)\right), \\
& =0\left(u^{\prime}\left(c_{0}\right) \lim _{t \rightarrow \infty} e^{-\int_{0}^{t} \frac{\gamma^{\prime}\left(k_{u}+\tilde{b}_{u}\right)}{u^{\prime}\left(c_{u}\right)} d u}\right), \\
& =0 .
\end{aligned}
$$

The transversality condition can therefore be expressed as:

$$
\lim _{t \rightarrow \infty} e^{-(\rho-n) t} u^{\prime}\left(c_{t}\right)\left[k_{t}+\tilde{b}_{t}\right]=0 .
$$


Let us finally show that there cannot be an equilibrium with an infinite value of $\varphi_{t}$. If $\varphi_{t}=-\infty$, then $\tilde{b}_{t}=b_{t}-\varphi_{t}=+\infty .{ }^{32}$ This implies $\gamma^{\prime}\left(k_{t}+\tilde{b}_{t}\right)=0$. From the above consumption Euler equation, we have:

$$
u^{\prime}\left(c_{t}\right)=u^{\prime}\left(c_{0}\right) e^{\int_{0}^{t}\left(\rho-r_{u}\right) d u} .
$$

The household's transversality condition is:

$$
\lim _{t \rightarrow \infty} e^{-(\rho-n) t} u^{\prime}\left(c_{t}\right)\left[k_{t}+b_{t}\right]=0 .
$$

It can therefore be simplified to:

$$
\lim _{t \rightarrow \infty} e^{-\int_{0}^{t}\left(r_{u}-n\right) d u}\left[k_{t}+b_{t}\right]=0 .
$$

Integrating the government liability accumulation equation (60) from $t$ to infinity yields $\lim _{T \rightarrow \infty} e^{-\int_{t}^{T}\left(r_{u}-n\right) d u} b_{T}=b_{t}-\varphi_{t}$ or, equivalently, $\lim _{T \rightarrow \infty} e^{-\int_{0}^{T}\left(r_{u}-n\right) d u} b_{T}=e^{-\int_{0}^{t}\left(r_{u}-n\right) d u} \tilde{b}_{t}=$ $\infty$. This implies that the household's transversality cannot be satisfied when $\varphi_{t}=-\infty$. $^{33}$

We have been able to replace $\left(\tau_{t}, b_{t}\right)_{t=0}^{\infty}$ by $\left(0, \tilde{b}_{t}\right)_{t=0}^{\infty}$ without changing any of the equations that characterize the equilibrium of the economy. Hence, the allocation $\left(c_{t}, k_{t}\right)_{t=0}^{\infty}$ must remain unchanged.

\section{N Proof of Lemma 14}

Under helicopter drops of money, we have $b_{t}=0$ and $\tau_{t}=-\omega m_{t}$ for all $t$. The present value of taxes is therefore given by:

$$
\begin{aligned}
\varphi_{t} & =\int_{t}^{\infty} e^{-\int_{t}^{s}\left(r_{u}-n\right) d u}\left(\tau_{s}+i_{s} m_{s}\right) d s \\
& =-\int_{t}^{\infty} e^{-\int_{t}^{s}\left(r_{u}-n\right) d u}\left(\omega-i_{s}\right) m_{s} d s .
\end{aligned}
$$

\footnotetext{
${ }^{32}$ Recall that, throughout our analysis, we exclusively focus on cases where the no-Ponzi condition is either binding or violated, i.e. $\tilde{b}_{t} \geq 0$.

${ }^{33}$ Note that, even if we impose the transversality condition $\lim _{t \rightarrow \infty} e^{-(\rho-n) t} u^{\prime}\left(c_{t}\right)\left[k_{t}+\tilde{b}_{t}\right]=0$, instead of $\lim _{t \rightarrow \infty} e^{-(\rho-n) t} u^{\prime}\left(c_{t}\right)\left[k_{t}+b_{t}\right]=0$, equilibria where $\tilde{b}_{t}$ tends to infinity are ruled out (since $u^{\prime}\left(c_{t}\right)$ asymptotically grows at rate $\rho-r$ while $\tilde{b}$ grows at rate $r-n$ ). There is therefore no need to impose the original household's transversality condition $\lim _{t \rightarrow \infty} e^{-(\rho-n) t} u^{\prime}\left(c_{t}\right)\left[k_{t}+b_{t}\right]=0$ to rule out such equilibria.
} 
The money supply equation (58) implies that:

$$
\begin{aligned}
\varphi_{t} & =-\int_{t}^{\infty} e^{-\int_{t}^{s}\left(r_{u}-n\right) d u}\left(\omega-i_{s}\right) m_{t} e^{\int_{t}^{s}\left(\omega-\pi_{u}-n\right) d u} d s \\
& =-m_{t} \int_{t}^{\infty}\left(\omega-i_{s}\right) e^{\int_{t}^{s}\left(\omega-i_{u}\right) d u} d s, \\
& =-m_{t} \int_{t}^{\infty} d\left(e^{\int_{t}^{s}\left(\omega-i_{u}\right) d u}\right) .
\end{aligned}
$$

Thus, for any given path of $i_{t}$, we must have:

$$
\varphi_{t}= \begin{cases}-\infty & \text { if } \omega>\lim _{t \rightarrow \infty} i_{t} \\ m_{t}\left[1-e^{\int_{t}^{\infty}\left(\omega-i_{u}\right) d u}\right] & \text { if } \omega=\lim _{t \rightarrow \infty} i_{t} . \\ m_{t} & \text { if } \omega<\lim _{t \rightarrow \infty} i_{t}\end{cases}
$$

This immediately implies that:

$$
\tilde{b}_{t}=m_{t}-\varphi_{t}= \begin{cases}\infty & \text { if } \omega>\lim _{t \rightarrow \infty} i_{t} \\ m_{t} e^{\int_{t}^{\infty}\left(\omega-i_{u}\right) d u} & \text { if } \omega=\lim _{t \rightarrow \infty} i_{t} \\ 0 & \text { if } \omega<\lim _{t \rightarrow \infty} i_{t}\end{cases}
$$

\section{O Proof of Proposition 3}

From the equilibrium conditions (70), (71), and (72), the steady state of the economy $(c, k, \tilde{b})$ must be jointly characterized by $\gamma^{\prime}(k+\tilde{b})=\left[\rho+\delta-f^{\prime}(k)\right] u^{\prime}(c), c=f(k)+z-$ $(\delta+n) k$, and either $f^{\prime}(k)-\delta=n$ or $\tilde{b}=0$. The steady state real interest rate satisfies $r=f^{\prime}(k)-\delta$.

In steady state, for any growth rate $\omega$ of the money supply, the path of real money balances $m_{t}$ must be consistent with these equations together with the magnitude of the Ponzi scheme $\tilde{b}_{t}$ given by Lemma 14 and the dynamic equation for real money balances (75), which in steady state is:

$$
\frac{\dot{m}_{t}}{m_{t}}=\omega-\frac{h^{\prime}\left(m_{t}\right)}{u^{\prime}(c)}+r-n
$$

Importantly, real money balances cannot be negative. Let $m$ be defined by $h^{\prime}(m)=$ $[\omega+r-n] u^{\prime}(c)$ whenever $\omega \geq-(r-n)$. From $(\mathrm{O} 1)$, there are three possibilities for the dynamics of real money balances:

- Constant real money balances: $m_{t}=m$.

- This is only possible if $\omega \geq-(r-n)$ since, otherwise, $m$ cannot be defined. 
- Speculative hyperinflation: $m_{0}<m$ (with $m=\infty$ if $\omega<-(\bar{r}-n)$ ) and $\lim _{t \rightarrow \infty} m_{t}=$ 0.

- This is only possible if $\lim _{x \rightarrow 0+} x h^{\prime}(x)=0$ since, otherwise, $m_{t}=0$ implies by (O1) that $\dot{m}_{t}<0$, which violates the $m_{t} \geq 0$ condition.

- Speculative deflation: $m_{0}>m$ and $\lim _{t \rightarrow \infty} m_{t}=\infty$.

- This is only possible if $\omega \geq-(r-n)$ since, otherwise, $m$ cannot be defined.

Let us now investigate the conditions under which these possibilities can arise when the economy is in steady state equilibrium.

We first consider the no-Ponzi steady state, where $\tilde{b}=0$ and $r=\bar{r}$. From equation (76) of Lemma 14 together with the money demand equation $h^{\prime}\left(m_{t}\right)=i_{t} u^{\prime}(c)$, we must have $\lim _{t \rightarrow \infty} h^{\prime}\left(m_{t}\right) / u(c)>\omega$. Equilibrium paths of $m_{t}$ are fully characterized by (O1) and $m_{t} \geq 0$, together with $\lim _{t \rightarrow \infty} h^{\prime}\left(m_{t}\right) / u(c)>\omega$. Thus, we just need to check that the above three possibilities are consistent with $\lim _{t \rightarrow \infty} h^{\prime}\left(m_{t}\right) / u(c)>\omega$.

- Constant real money balances: $m_{t}=m$ where $m$ is the solution to $h^{\prime}(m)=$ $[\omega+\bar{r}-n] u^{\prime}(c)$ implies that $\lim _{t \rightarrow \infty} h^{\prime}\left(m_{t}\right) / u(c)=h^{\prime}(m) / u^{\prime}(c)=\omega+\bar{r}-n$, which must be greater than $\omega$. This can only be an equilibrium under the additional requirement that $\bar{r}>n$.

- Speculative hyperinflation: $\lim _{t \rightarrow \infty} m_{t}=0$ implies that $\lim _{t \rightarrow \infty} h^{\prime}\left(m_{t}\right) / u(c)=+\infty$, which is always greater than $\omega$. This is always an equilibrium, with no additional requirement.

- Speculative deflation: $\lim _{t \rightarrow \infty} m_{t}=\infty$ implies that $\lim _{t \rightarrow \infty} h^{\prime}\left(m_{t}\right) / u(c)=0$, which must be greater than $\omega$. This can only be an equilibrium under the additional requirement that $\omega<0$.

We now consider the Ponzi steady state, where $\tilde{b}>0$ and $r=n$. From Proposition 2 , we know that it is only feasible when $\bar{r}<n$. From Lemma 14 together with the money demand equation $h^{\prime}\left(m_{t}\right)=i_{t} u^{\prime}(c)$, we must have $\tilde{b}=m_{t} e^{\int_{t}^{\infty}\left(\omega-\frac{h^{\prime}(m)}{u^{\prime}(c)}\right) d u}$ and $\lim _{t \rightarrow \infty} h^{\prime}\left(m_{t}\right) / u^{\prime}(c)=\omega$, where $\tilde{b}$ is the solution to $\gamma^{\prime}(k+\tilde{b})=(\rho-n) u^{\prime}(c) \cdot{ }^{34}$ Using

\footnotetext{
${ }^{34}$ From Proposition 2, we know that $\tilde{b}>0$ whenever $\bar{r}<n$.
} 
the dynamics of real money balances (O1) with $r=n$, we have:

$$
\begin{aligned}
\tilde{b} & =m_{t} e^{\int_{t}^{\infty}\left(\omega-\frac{h^{\prime}\left(m_{u}\right)}{u^{\prime}(c)}\right) d u}, \\
& =m_{t} e^{\int_{t}^{\infty} \frac{\dot{m}_{u}}{m_{u}} d u}, \\
& =m_{t} e^{\int_{t}^{\infty} d \ln \left(m_{u}\right)}, \\
& =m_{t} \lim _{T \rightarrow \infty} e^{\ln \left(m_{T} / m_{t}\right)}, \\
& =\lim _{T \rightarrow \infty} m_{T} .
\end{aligned}
$$

Combining this with the requirement that $\lim _{t \rightarrow \infty} h^{\prime}\left(m_{t}\right) / u^{\prime}(c)=\omega$ gives $\omega=h^{\prime}(\tilde{b}) / u^{\prime}(c)$.

Thus, when $\omega=h^{\prime}(\tilde{b}) / u^{\prime}(c)$, any path of real money balances satisfying $\lim _{t \rightarrow \infty} m_{t}=\tilde{b}$ is consistent with the Ponzi steady state. But, by (O1) with $r=n$, the path of real money balances is given by:

$$
\frac{\dot{m}_{t}}{m_{t}}=\frac{h^{\prime}(\tilde{b})}{u^{\prime}(c)}-\frac{h^{\prime}\left(m_{t}\right)}{u^{\prime}(c)}
$$

Clearly, the only solution consistent with $\lim _{t \rightarrow \infty} m_{t}=\tilde{b}>0$ is to have $m_{t}=\tilde{b}$ for all $t$. 